\title{
Assessment of Deployment Scenarios of New Fuel Cycle Technologies
}

\author{
J. J. Jacobson, G. E. Matthern and S. J. Piet \\ Idaho National Laboratory \\ United States
}

\section{Introduction}

There is the beginning of a nuclear renaissance. High energy costs, concern over fossil fuel emissions, and energy security are reviving the interest in nuclear energy. There are a number of driving questions on how to move forward with nuclear power. Will there be enough uranium available? How do we handle the used fuel, recycle or send to a geologic repository? What type of reactors should be developed? What type of fuel will they need?

\section{Why assess deployment scenarios?}

Nuclear fuel cycles are inherently dynamic. However, fuel cycle goals and objectives are typically static.1,2,3 Many (if not most) comparisons of nuclear fuel cycle options compare them via static time-independent analyses. Our intent is to show the value of analyzing the nuclear fuel cycle in a dynamic, temporal way that includes feedback and time delays.

Competitive industries look at how new technology options might displace existing technologies and change how existing systems work. So too, years of performing dynamic simulations of advanced nuclear fuel cycle options provide insights into how they might work and how one might transition from the current once-through fuel cycle.

Assessments can benefit from considering dynamics in at least three aspects - A) transitions from one fuel cycle strategy to another, B) how fuel cycles perform with nuclear power growth superimposed with time delays throughout the system, and C) impacts of fuel cycle performance due to perturbations.

To support a detailed complex temporal analysis of the entire nuclear fuel cycle, we have developed a system dynamics model that includes all the components of the nuclear fuel cycle. VISION tracks the life cycle of the strategic facilities that are essential in the fuel cycle such as, reactors, fuel fabrication, separations and repository facilities. The facility life cycle begins by ordering, licensing, construction and then various stages of on-line periods and finally decommission and disposition. Models need to allow the user to adjust the times for various parts of the lifecycle such as licensing, construction, operation, and facility lifetimes. Current energy production from nuclear power plants in the once through approach is linear. Uranium is mined, enriched, fabricated into fuel, fed to nuclear reactor, removed from a nuclear reactor and stored for future disposal. This is a once through cycle, with no real "cycle" involved. Future fuel cycles are likely to be real cycles where nuclear fuel and other materials may be reused in a nuclear reactor one or more times. This will increase the 
dependency among the steps in the process and require a better understanding of the technical limitations, the infrastructure requirements, and the economics. All three of these elements are time dependent and cyclical in nature to some degree. Understanding how these elements interact requires a model that can cycle and evolve with time - a dynamic model. Understanding these new fuel cycles also requires extrapolation beyond current fuel cycle operating experience. The goal is not to be able to predict the exact number or size of each of the elements of the fuel cycle, but rather to understand the relative magnitudes, capacities, and durations for various options and scenarios. A systems-level approach is needed to understand the basics of how these new fuel cycles behave and evolve.

\section{Vision nuclear fuel cycle model}

The Verifiable Fuel Cycle Simulation (VISION) model was developed and is being used to analyze and compare various nuclear power technology deployment scenarios ${ }^{4}$. The scenarios include varying growth rates, reactor types, nuclear fuel and system delays. Analyzing the results leads to better understanding of the feedback between the various components of the nuclear fuel cycle that includes uranium resources, reactor number and mix, nuclear fuel type and waste management. VISION links the various fuel cycle components into a single model for analysis and includes both mass flows and decision criteria as a function of time.

This model is intended to assist in evaluating "what if" scenarios and in comparing fuel, reactor, and fuel processing alternatives at a systems level. The model is not intended as a tool for process flow and design modeling of specific facilities nor for tracking individual units of fuel or other material through the system. The model is intended to examine the interactions among the components of the nuclear fuel system as a function of time varying system parameters; this model represents a dynamic rather than steady-state approximation of the nuclear fuel system.

\subsection{VISION introduction}

VISION tracks the flow of material through the entire nuclear fuel cycle. The material flows start at mining and proceed through conversion, enrichment, fuel fabrication, fuel in and out of the reactor and then used fuel management, either recycling, storage, or final waste disposition. Each of the stages in the fuel cycle includes material tracking at the isotopic level, appropriate delays and associated waste streams. VISION is able to track radioactive decay in any module where the material resides for a minimum of a year.

VISION also tracks the life cycle of the strategic facilities that are essential in the fuel cycle such as, reactors, fuel fabrication, separations, spent fuel storage and conditioning and repository facilities. The life cycle begins by ordering, licensing, construction and then various stages of on-line periods and finally decommission and disposition. The model allows the user to adjust the times for various parts of the lifecycle such as licensing time, construction time and active lifetime.

VISION calculates a wide range of metrics that describe candidate fuel cycle options, addressing waste management, proliferation resistance, uranium utilization, and economics. For example, waste metrics include the mass of unprocessed spent fuel, mass in storage, final waste mass and volume, long-term radiotoxicity, and long-term heat commitment to a geologic repository. Calculation of such metrics requires tracking the flow of 81 specific isotopes and chemical elements. ${ }^{5}$

Figure 1 is a schematic of a nuclear fuel cycle, which is organized into a series of modules that include all of the major facilities and processes involved in the fuel cycle, starting with 
uranium mining and ending with waste management and disposal. The arrows in the diagram indicate the mass flow of the material. Not shown, but included in each module within the model, are the information and decision algorithms that form the logic for the mass flow in VISION. The mass flows are combined with waste packaging data to provide insight into transportation issues of the fuel cycle.

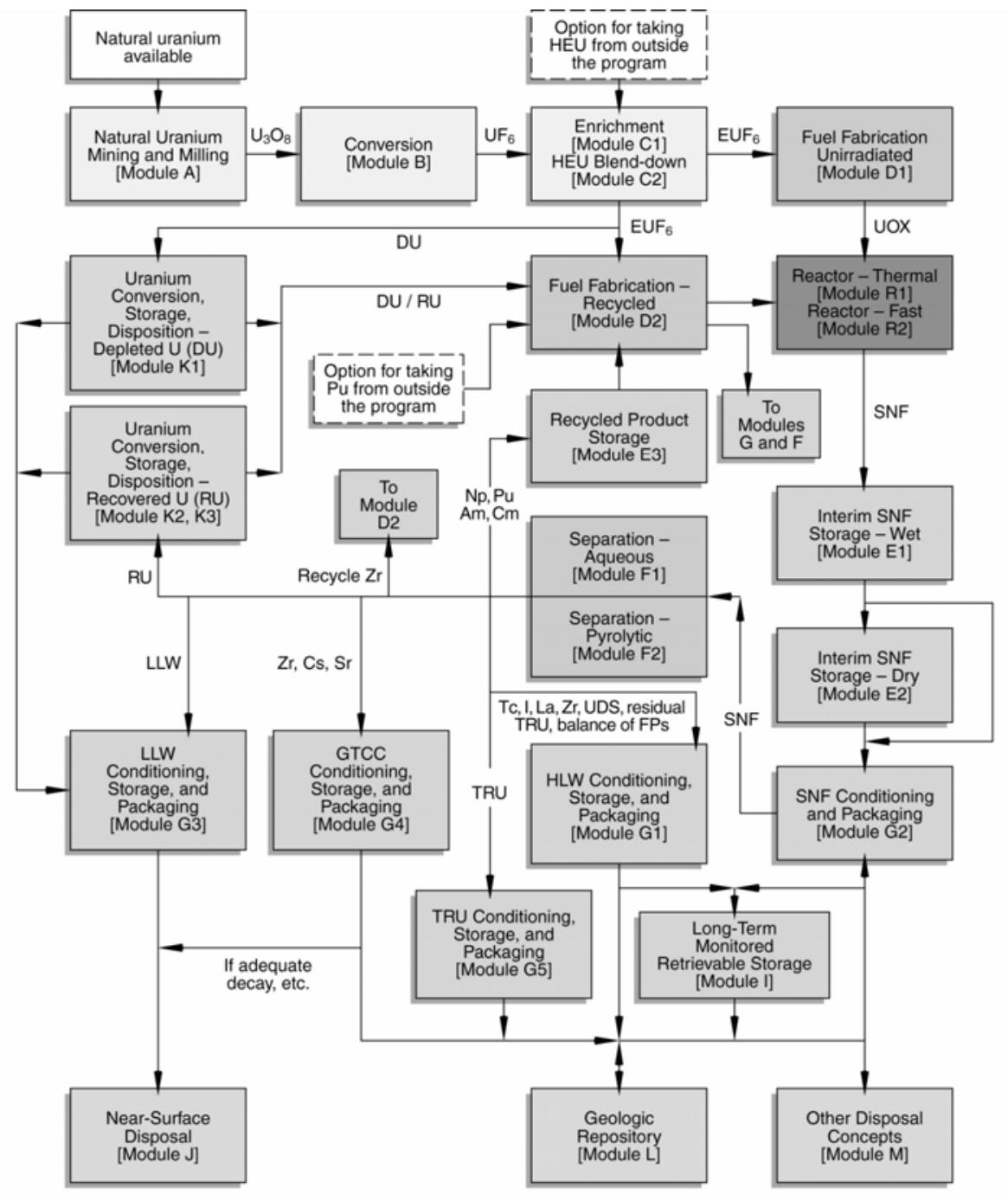

Transportation Processes for High-Level Radioactive Materials (SNF, HLW, TRU, LLW-GTCC, recycled fuel) [Module O1]

Transportation Processes for Low-Level Radioactive Materials (LLW-near-surface, unirradiated fuel, RU, DU, EU) [Module O2]

Fig. 1. Schematic of VISION modules representing the nuclear fuel cycle processes and facilities. 


\subsection{VISION functionality}

VISION is designed around the methodology of system dynamics. System dynamics is a computer-based method for studying dynamic, problematic behavior of complex systems. The method emerged in the 1960s from the work of Jay Forrester at the Sloan School of Management at Massachusetts Institute of Technology. A detailed description of the system dynamics approach was first given in "Principles of Systems". 6 VISION is designed to run on a desktop personal computer with run times less than 10 minutes for any single scenario simulated over a 200 -year period. Users can run scenarios by selecting pre-defined base cases or by modifying the options that make up a scenario. Currently, there are approximately 60 predefined scenarios available that range from the more simple case of thermal reactors without recycling to more advanced cases that include advanced reactor types such as fast reactors with various recycle options. Results are displayed in a variety of charts and graphs that are part of the interface or the user can open up the Excel charts that include many more tables and charts. The charts include comparative charts of data within the scenario such as the number of light water reactors (LWR) versus Fast Reactors.

VISION simulates the nuclear fuel cycle system with as many of its dynamic characteristics as possible, to name a few, it simulates impacts from delays, isotopic decay, capacity building and fuel availability. The VISION model has three modes of reactor ordering, the first takes a projected energy growth rate and nuclear power market share over the next century and builds reactors in order to meet this demand, second the user can manually set the number of reactors that are ordered each year and lastly, the user can specify an end of the century target in GWe and allow the model to build reactors to meet that projection. Options are included in the model that allow the user to recycle used nuclear fuel with up to 10 different separation technologies, use up to 10 different reactor and fuel types, and have up to 15 different waste management options. The technology performance can be varied each year. The results of the model will help policy makers and industry leaders know and understand the impacts of delays in the system, infrastructure requirements, material flows, and comparative metrics for any combination of advanced fuel cycle scenarios.

The subsections below describe key algorithms and approaches that comprise VISION's functionality. The first several subsections address the issue of when new facilities are ordered. VISION has a complex look-ahead ordering algorithm for new facilities. The user can override this instead and force the model to build facilities by inputting the capacity for each type of facility. The discussion on facility ordering entails subsections on facilities themselves as an introduction, supplies needed for the facility, and outputs from each facility. After ordering facilities, the section turns to energy growth rate, and then the physics issues of which isotopes are tracked in VISION and how VISION uses reactor physics data.

\subsubsection{Facilities}

The mathematical model for ordering facilities is based upon a demand-supply model, where facilities for one or more stages of the fuel cycle create demand, which is serviced by the supply produced by facilities for another stage. The overall driver triggering the demand is electrical energy growth and nuclear power market share that is expected over the next 200 years.

To further explain the ordering process by way of example, for a closed (recycle) fuel cycle, the future electrical energy demand will require increased supply of electrical energy. If this supply is not adequate, new nuclear power plants will need to be built. In turn, this will 
result in an increased demand for fuel fabrication services. If supply and usable inventory is not adequate, new fuel fabrication plants will be built; this will result in an increased demand for separation services. Again, if supply and usable inventory is not adequate, new separation plants will be built, which will result in an increased demand for used fuel. If supply and usable inventory is not adequate for this, new nuclear power plants will be built, bringing us back to the beginning of the cycle.

Note that a circular logic has developed, where we started with building new nuclear power plants due to electrical demand and return to this at the end due to used fuel demand. This implies that some decisions, e.g., mix of light water reactor multiple fuels (LWRmf) (multiple fuels means uranium oxide (UOX), mixed oxide (MOX) or inert matrix fuel (IMF)) and fast consumer/breeder reactor (FBR) or conversion ratio of FBR, must be made such that the starting and ending states are consistent. In order to prevent a mismatch of fuel available for advanced reactors which rely on used fuel from LWR and LWRmf reactors for their fuel supply, a predicted used fuel calculation must be performed at the time of ordering reactors that will inform the system how much used fuel is available for use in advanced reactors.

This demand function looks a certain number of years into the future $\left(t+\Delta t^{x}\right)$, where $t$ is the current time and $\Delta \mathrm{t}^{\mathrm{x}}$ is the time it takes to license and build a supply facility of type "x." The demand function also projects out to the year $t^{\prime}$, where $t^{\prime}$ is the year that demand facilities utilize the services provided by supply facilities.

The demand function (Eq. 1) is as follows:

$$
D_{t+\Delta t^{x}}^{x}=\sum_{y, t^{\prime} \geq t+\Delta t^{x}} \gamma_{t^{\prime} \rightarrow t+\Delta t^{x}}^{y \rightarrow x} N_{t^{\prime}}^{y} C_{t^{\prime}}^{y}
$$

$D_{t}^{x}$ - Demand rate for time period " $\mathrm{t}$ " for service or product of facility of type " $\mathrm{x}$ " based on the number of type " $y$ " facilities that are operating at time period $t$ '.

$N_{t^{\prime}}^{y}$ - Number of operating facilities of type " $y$ " at time $t^{\prime}$ that require the service from type " $x$ " facility. This includes planned facilities and those now operating at " $t$ " that will continue to operate at $t^{\prime}$.

$C_{t^{\prime}}^{y}-\quad$ Expected capacity factor for facilities of type " $y$ " at time $t^{\prime}$.

$\gamma_{t^{\prime} \rightarrow t+\Delta t^{x}}^{y \rightarrow x}$ - Conversion factor that converts the demand rate for time period $t^{\prime}$ for service or product of facility " $\mathrm{y}$ " into a demand rate for time period " $t+\Delta t^{x}$ " for service or product of facility " $x$ " that will service facility " $y$. . It is assumed that the product or service of facility " $x$ " can be produced over one time period, e.g., one year, which implies $\gamma_{t^{\prime} \rightarrow t+\Delta t^{x}}^{y \rightarrow x}$ only takes on a nonzero value for one value of $\mathrm{t}^{\prime}$ when $t^{\prime}-\left(t+\Delta t^{x}\right)=$ time to start offering/production of service/product of facility " $x$ " to have completed, i.e., manufactured + delivered + stored, for facility "y."

The supply function takes the number of operating facilities and their respective availabilities and determines how much available supply of a certain service via production there is in the system. The supply function (Eq. 2) is as follows:

$$
S_{t+\Delta t}^{x}=\beta^{x} N_{t+\Delta t}^{x} C_{t+\Delta t}^{x}
$$


$S_{t+\Delta t^{x}}^{x}$ - Rated supply rate of product at " $t+\Delta t^{x}$ " that can be produced by type " $x$ " facility.

$N_{t+\Delta t^{x}}^{x}$ - Number of operating facilities of type " $x$," including planned facilities and those now operating who at " $t+\Delta t^{x}$ " will continue to operate.

$C_{t+\Delta t}^{x}$ - Capacity factor of facility type " $x$ " that is in operation.

$\beta^{x}$ - Converts the number of facilities of type " $x$ " into a supply rate of type " $x$."

The capacity factor, $C_{t+\Delta t}^{x}$, is a user defined function which typically depends on maturity level of the technology. For instance, capacity factor for LWR's is set at around 90\%, for new Fast Reactor's it would probably be set closer to $80 \%$. Such choices are made by the user.

In order to get the current demand, or the demand for services that the system is currently requesting, simply take Equation 1 and set $\Delta \mathrm{t}^{\mathrm{x}}$ equal to zero. This will make the demand function equal to the current demand to produce a product or service. This demand (Eq. 3) will be labeled $\hat{D}_{t}^{x}$ for further use in the methodology.

$$
\hat{D}_{t}^{x}=\sum_{y, t^{\prime} \geq t} \gamma_{t^{\prime} \rightarrow t}^{y \rightarrow x} N_{t^{\prime}}^{y} C_{t^{\prime}}^{y}
$$

In order to get the current supply, simply set the $\Delta \mathrm{t}^{\mathrm{x}}$ in Equation 2 equal to zero. This will cause the equation to only use the facilities that are in operation at the current time " $t$." The current supply (Eq. 4) will be labeled $\hat{S}_{t}^{x}$ for further use in the methodology.

$$
\hat{S}_{t}^{x}=\beta^{x} N_{t}^{x} A_{t}^{x}
$$

The actual available output of facilities is based on the capacity factor of the facilities of type "x." The capacity factor (Eq. 5) will change automatically for the system as new facilities come online and start requesting services. The capacity factor is a user defined value that is typically adjusted upward as more facilities come on line from an initial low capacity factor representing new types of facilities to a theoretical high value for facility with years of operational experience.

$$
\mathrm{O}_{\mathrm{t}}^{\mathrm{x}}=\beta^{x} N_{t}^{x} C_{t}^{x}
$$

$\mathrm{O}_{\mathrm{t}}^{\mathrm{x}}$ - Actual output of facility of type " $\mathrm{x}$ " at time " $t$."

$\beta^{x}$ - Converts the number of facilities of type " $x$ " into a supply rate of type " $x$. ."

$C_{t}^{x}$ - Capacity factor for facilities of type " $\mathrm{x}$ " at time " $\mathrm{t}$."

In order to implement this methodology, a projected energy demand growth and used fuel prediction is calculated in order to determine the number and type of reactors that can come online. The model looks ahead a prescribed number of years (the longest construction time of all of the facilities plus time to manufacture and deliver the product) and calculate supply and demand for reactors, fuel fabrication, and separations. At the beginning of the simulation, before the first time step, the model calculates the energy growth for every year of the simulation plus the number of years the model is looking ahead. The growth function (Eq. 6) is as follows:

$$
E_{t}=E_{t-1} *\left(1+p_{t} / 100\right)
$$


where $E_{t}$ in (Eq. 6) is the electric demand at year $\mathrm{t}$ and $p_{t}$ is the growth percentage at year $\mathrm{t}$. When the function reaches the last growth rate $p_{100}$ provided by the input, it will hold that value in order to project out values beyond the 200-year time period.

The next step is to calculate the number of reactors that need to be ordered based on the growth rate and energy gap during the initial look-ahead time. During the initial look-ahead time, $\Delta t_{\text {look }}$, the model will only build LWRmf reactors because it is assumed that there will not be any FBRs deployed before the initial look-ahead time. The initial number of reactors for each of the look-ahead years is stored in an initialization vector so that at the beginning of the simulation the model will know how many reactors need to come online and when they need to come online. These reactors are then sent to an order rate array $(\overline{R O})$ where they will be stored and called upon when it is time to order reactors. As the model starts, the simulation will progress forward with the $t$ variable moving one year out for each year of the simulation. Reactors during the initial look-ahead time will be built based on the initial estimate of reactor ordering at the start of the simulation As the simulation moves forward, new reactors after the initial look ahead years are ordered based on the energy growth rate and energy gap that is predicted in those future years. That is, if the initial look ahead is 20 years, in year 2001 and estimate will be made on energy growth and energy gap in 2021 and reactors will be ordered that will meet that demand.

The model runs for a specified time period - typically, from year 2000 to year 2200. The user can define a growth rate that nuclear power will grow at and allow the model to determine the number of reactors that are ordered to meet the demand or the user can be more specific and specify the reactor numbers. The model allows the user to define which reactor types to activate at specific times throughout the simulation period. In addition, the user can define the specific fuel to use in each reactor type, as well as the separation technology available and the capacities for all facilities in the fuel cycle (i.e., fuel fabrication, separations, etc.).

For each reactor type the user can set a variety of operational parameters, such as thermal efficiency, load factor, power level, and fuel residence time. In addition, the user can also set time parameters, such as reactor construction time, licensing time, reactor lifetime, used fuel wet storage time, separations time, and fuel fabrication time. Additional parameters can be set to adjust fuel fabrication rate, repository acceptance rate, and separations capacity and processing rate. Overall, there are over 200 parameters that the user can set and adjust between simulations. Because of the large number of parameters, there are a number of predefined scenarios that the user can select from a menu. These predefined scenarios set all the parameters for the selected scenario so these cases can be run with minimal effort.

\subsubsection{Tracked isotopes}

VISION tracks mass at an isotopic level, which is valuable from several aspects. First, the model is able to calculate some important metrics, such as, decay heat, toxicity and proliferation resistance. Second, it allows the model to use specific isotopes, such as Plutonium, for flow control in separations and fuel fabrication based on availability of Pu239, Pu240 and Pu241 from separated spent fuel. Lastly, it allows the estimate of isotopic decay whenever the material is residing in storage of at least 1 year.

Table I lists the 81 isotopes that VISION currently tracks the main fuel flow model. For the four radionuclide actinide decay chains $(4 \mathrm{~N}, 4 \mathrm{~N}+1,4 \mathrm{~N}+2,4 \mathrm{~N}+3)$, it will track all isotopes with half-life greater than 0.5 years, with the exception of 5 isotopes whose inventory 


\begin{tabular}{|c|c|c|c|}
\hline \multicolumn{2}{|c|}{ Actinides and Decay Chain } & \multicolumn{2}{|l|}{ Fission Products } \\
\hline $\mathrm{He} 4$ & & $\mathrm{H} 3$ & \multirow[t]{3}{*}{ Other gases } \\
\hline $\mathrm{Pb} 206$ & \multirow{5}{*}{ Transition Metals } & C14 & \\
\hline $\mathrm{Pb} 207$ & & C-other & \\
\hline $\mathrm{Pb} 208$ & & Kr81 & \multirow[t]{3}{*}{ Inert gases (Group 0) } \\
\hline $\mathrm{Pb} 210$ & & Kr85 & \\
\hline Bi209 & & Inert gas other $(\mathrm{Kr}, \mathrm{Xe})$ & \\
\hline Ra226 & \multirow{2}{*}{ Group 2A } & $\mathrm{Rb}$ & \multirow[t]{3}{*}{ Group 1A/2A } \\
\hline Ra228 & & Sr90 w/Y90 decay & \\
\hline Ac227 & \multirow[t]{6}{*}{ Actinides } & Sr-other & \\
\hline Th228 & & Zr93 w/Nb93m decay & \multirow[t]{3}{*}{ Zirconium } \\
\hline Th229 & & Zr95 w/Nb95m decay & \\
\hline Th230 & & Zr-other & \\
\hline Th232 & & Tc99 & \multirow[t]{2}{*}{ Technetium } \\
\hline Pa231 & & Tc-other & \\
\hline $\mathrm{U} 232$ & \multirow[t]{6}{*}{ Uranium } & Ru106 w/Rh106 decay & \multirow{3}{*}{$\begin{array}{l}\text { Transition metals that } \\
\text { constrain glass waste forms }\end{array}$} \\
\hline $\mathrm{U} 233$ & & Pd107 & \\
\hline $\mathrm{U} 234$ & & Mo-Ru-Rh-Pd-other & \\
\hline $\mathrm{U} 235$ & & Se79 & \multirow[t]{5}{*}{ Other transition metals } \\
\hline U236 & & Cd113m & \\
\hline $\mathrm{U} 238$ & & Sn126 w/Sb126m/Sb126 & \\
\hline $\mathrm{Np} 237$ & Neptunium & Sb125 w/Te125m decay & \\
\hline Pu238 & \multirow[t]{6}{*}{ Plutonium } & $\begin{array}{l}\text { Transition Metal-other (Co-Se, Nb, } \\
\text { Ag-Te) }\end{array}$ & \\
\hline Pu239 & & I129 & \multirow[t]{2}{*}{ Halogens (Group 7) } \\
\hline Pu240 & & Halogen-other (Br, I) & \\
\hline Pu241 & & Cs134 & \multirow[t]{5}{*}{ Group 1A/2A } \\
\hline Pu242 & & Cs135 & \\
\hline Pu244 & & Cs137 w/Ba137m decay & \\
\hline Am241 & \multirow{3}{*}{ Americium } & \begin{tabular}{|l|} 
Cs-other \\
\end{tabular} & \\
\hline Am242m & & $\mathrm{Ba}$ & \\
\hline Am243 & & Ce144 w/Pr144m/Pr144 decay & \multirow[t]{9}{*}{ Lanthanides } \\
\hline $\mathrm{Cm} 242$ & \multirow[t]{8}{*}{ Curium } & Pm147 & \\
\hline $\mathrm{Cm} 243$ & & Sm146 & \\
\hline $\mathrm{Cm} 244$ & & Sm147 & \\
\hline $\mathrm{Cm} 245$ & & Sm151 & \\
\hline $\mathrm{Cm} 246$ & & Eu154 & \\
\hline $\mathrm{Cm} 247$ & & Eu155 & \\
\hline $\mathrm{Cm} 248$ & & Ho166m & \\
\hline Cm250 & & LA-other plus Yttrium & \\
\hline Bk249 & Berkelium & & \\
\hline Cf249 & \multirow[t]{4}{*}{ Californium } & & \\
\hline Cf250 & & & \\
\hline Cf251 & & & \\
\hline Cf252 & & & \\
\hline
\end{tabular}

Table 1. Tracked Isotopes and Chemical Elements 
appears never to be significant. For fission products, VISION calculates isotopes found to dominate each possible waste stream, $\mathrm{CsSr}$ (Group 1A/2A), halogens, inert gases, transition metals, Zr, Tc, lanthanides, H-3, and C-14. In each case, both key radioactive isotopes and stable mass must be tracked because for the key elements, it is needed to calculate the mass of the key fission product divided by the total mass of that element. For example, to assess the "CsSr" waste option, VISION tracks Sr90 (with Y90 decay energy), Cs134, Cs135, Cs137 (with Ba137m decay energy), stable Rb, other Sr mass, other Cs mass, and stable Ba.

Only isotopes with halflife greater than 0.5 year are candidates for being tracked in fuel cycle simulations. A half year is two VISION time steps when running simulations with the typical 0.25 -year time step. Not tracking such short-lived isotopes does not significantly impact mass and radiotoxicity assessments. (Spot checks of gamma and heat indicate the same thing.) Short-lived progeny of other isotopes, however, must be considered. Their heat and decay energy emission must be included when their parent isotopes decay. For example, Y90 decay energy must be included with decay of Sr90.

For actinide and decay chain isotopes, we started with all isotopes with halflife greater than 0.5 year. The behavior of actinide and decay chain isotopes is so complex that we essentially have to include all isotopes with halflife greater than 0.5 years. However, we do discard five of the candidate isotopes (Np235, Np236, Pu236, Cf248, and Es254) because their yield is so low. In subsequent calculations of radiotoxicity, heat, etc, the decay input of those isotopes less than 0.5 years must be accounted for as being in equilibrium with longer-lived parents.

Compared to actinide and decay chain isotopes, the complexity of behavior is less and the number of candidate isotopes is greater for fission products. We started with the set of fission product isotopes previously studied in Advanced Fuel Cycle Initiative (AFCI) system studies and added isotopes (and blocks of "stable" elements) such that the mass and radiotoxicity of each of the candidate waste streams (inert gases, lanthanides, CsSr, transition metal, Tc, halogens) calculated from the reduced set of isotopes and elements was within a few percent of calculations using all the isotopes for UOX at $51 \mathrm{MWth}-\mathrm{day} / \mathrm{kg}-\mathrm{iHM}$ burnup.

The current version of the code evaluates the heat loads, radiotoxicity, proliferation metrics and other parameters at key location in the fuel cycle (repository, dry storage, etc.). For separation and recycle of used thermal fuel, the youngest (shortest time out of the reactor) and then least cycled fuel has priority for the available capacity. The repository capacity can be varied with time, and includes permanent and retrievable capacities, and the rate material can be sent to the repository can also be varied with time. In contrast to separations, the oldest (longest time out of the reactor) and then most cycled fuel has priority for the repository.

\subsubsection{Neutronics parameters}

A key feature of the VISION model is that direct neutronics calculations are not performed within model, which makes it much simpler and more user friendly compared to other fuel cycle system codes that include this type of calculations such as COSI and NFCSIM codes. 8,9 The neutronics calculations are made external to the model and parameters from those calculations are used as fixed parameters within the model. The important parameters are the composition of fresh and spent fuel that corresponds to a certain type of reactor/fuel, and the initial reactor core loading and the loading per a batch of fuel. More than one composition vector (recipe) can be provided for the same fuel, e.g., in case of recycling in 
fast reactors, a non-equilibrium (startup) composition is needed for early cycled fuel and an equilibrium (recycle) composition is needed for fuel cycled greater than or equal to 5 times. Users can input whatever input/output fuel recipes they wish.

Most of our calculations have been done with LWR uranium oxide (UOX) with an initial enrichment of 4.3\% U-235 and a discharge burnup of 51,000 MWth-day/tonne-iHM. ${ }^{10}$ Other sources of data include Hoffman, Asgari, Ferrer, and Youinou.11,12,13,14,15,16 The user can alternatively input their own input and output isotopic recipes.

Transmutation in low conversion ratio fast reactor is based on a compact fast burner reactor design that can achieve low conversion ratios. ${ }^{11}$ This design is the basis for all transmutation options that used TRU from UOX, MOX or IMF spent fuel into a burner fast reactor in the VISION calculations.

\subsection{Simulation}

The real power of simulation models lies in learning insights into total system behavior as time, key parameters, and different scenarios (e.g. growth rate, reactor type) are considered. This is more valuable (and more credible) than attempting to make design and management decisions on the basis of single-parameter point estimates, or even on sensitivity analyses using models that assume that the system is static. System dynamic models allow users to explore long-term behavior and performance, especially in the context of dynamic processes and changing scenarios. When comparing different management/design scenarios did the system perform better or worse over the long term?

System dynamic models serve many of the same purposes as flight simulators. Indeed, the reason the user input is described as a "cockpit" is that such a model allows the designer/stakeholder to simulate management of the system over time. After repeated simulations, a student pilot gains deeper understanding of how the aircraft systems will respond to various perturbations (none of which will exactly match a real flight) - without the expense and risk of gaining such experience solely in real flights. Instead of simulating an aircraft flight, VISION simulates the nuclear fuel cycle system with as many of its dynamic characteristics as possible. This allows decision makers and developers to learn how the fuel cycle system may respond to time and various perturbations - without having to wait decades to obtain data or risk a system disconnect if a poor management strategy is used. VISION also allows users to test a range of conditions for parameters such as energy growth rate and licensing time which are not controlled by developers of nuclear energy but affect its implementation so that robust and flexible strategies can be identified to address uncertainties. For high-stakes strategy analysis, a system dynamics model, as a result of upfront scientific work, is easier to understand, more reliable in its predictions, and ultimately far more useful than discussion and debate propped up by traditional data analysis techniques such as histograms, Pareto charts and spreadsheets. System Dynamics is an analytical approach that examines complex systems through the study of the underlying system structure. By understanding a system's underlying structure, predictions can be made relative to how the system will react to change.

\section{Illustrative deployment scenario simulations}

The examples in this chapter are based on the following fuel cycles:

- Once through, Light Water Reactor (LWR) with uranium oxide (UOX) fuel at 51 GWthday/tonne-iHM burnup. 
- $\quad$ MOX recycle, Light Water Reactor (LWR) with a combination of mixed oxide fuel (MOX) and uranium oxide fuel (UOX).

- 2-tier, plutonium and uranium from LWR-UOX are first recycled once in LWR as mixed oxide (MOX) fuel. The remaining material and the minor actinides from separation of used LWR-UOX are then recycled in fast reactors.

- 1-tier, transuranic material from LWR-UOX is recycled in fast reactors with a range of transuranic (TRU) conversion ratios (CR) from 0.00 to 1.1. The TRU CR is defined as the production of transuranic material divided by all destruction pathways of transuranic material.

\subsection{Illustrative assumptions and input parameters}

All of the examples below use the following assumptions:

- Analysis of US domestic systems

- Growth of nuclear energy is flat until 2015, when it resumes growth at an annual rate of $1.75 \%$, resulting in 200 GWe-year of electricity generated in 2060 and 400 GWe-year in 2100. (Current annual output is 86 GWe-year.)

- A centralized facility accepts LWR used fuel for direct disposal starting in 2017 and ending in 2039 for a total of 63,000 MTiHM. For the once-through case, additional used fuel is disposed in generic additional repository capacity when sufficiently cooled (20 years). For the closed fuel cycle cases, additional used fuel is recycled.

The MOX, 2-tier and 1-tier examples also use the following assumptions:

- Separation of LWR used fuel begins in 2020, initially with a small plant (800 $\mathrm{MTiHM}$ /year capacity) with additional plants added as needed to work off any excess stores of used fuel by 2100. LWR used fuel is cooled 10 years before shipment for recycling. The TRU from separations is used to make recycle fuel (either MOX-Pu for LWRs or TRU fuel for fast reactors).

- The MOX cycle takes at least 15 years (5 years in the reactor, 10 years cooling) before the used fuel is available for recycle as MOX in thermal reactors or in fast reactors.

- A small fast reactor starts up in 2022 to prove the reactor and transmutation fuel technologies. Follow-on commercial fast reactors use a TRU conversion ratio (CR) of 0.5 , metal fuel, and on-site recycling. (Sensitivity studies examine other options.)

- For the 1-tier scenario, commercial fast reactors follow 10 years later (2032), with construction rates limited for the first decade to allow for learning.

- For the 2-tier scenario, the MOX cycle takes at least 15 years before the used fuel is available for recycle into fast reactor fuel, so commercial fast reactors are delayed 15 years (to 2047).

- All TRU elements are recovered whenever used fuel is separated. Cesium and Strontium (CsSr) together are separate waste products. Separations losses are defined by the user with the default of $0.1 \%$ processing loss.

The once-through scenario provides the basis for comparison with the closed fuel cycle scenarios (fuel recycle). All electricity generation is based on LWRs using standard UOX fuel. The growth curve is depicted in figure 2 and shows the current growth "pause", with no new reactors until 2015. After 2015, growth is modeled with simple compounding at $1.75 \%$. This growth rate assumes nuclear energy use for electricity only. 


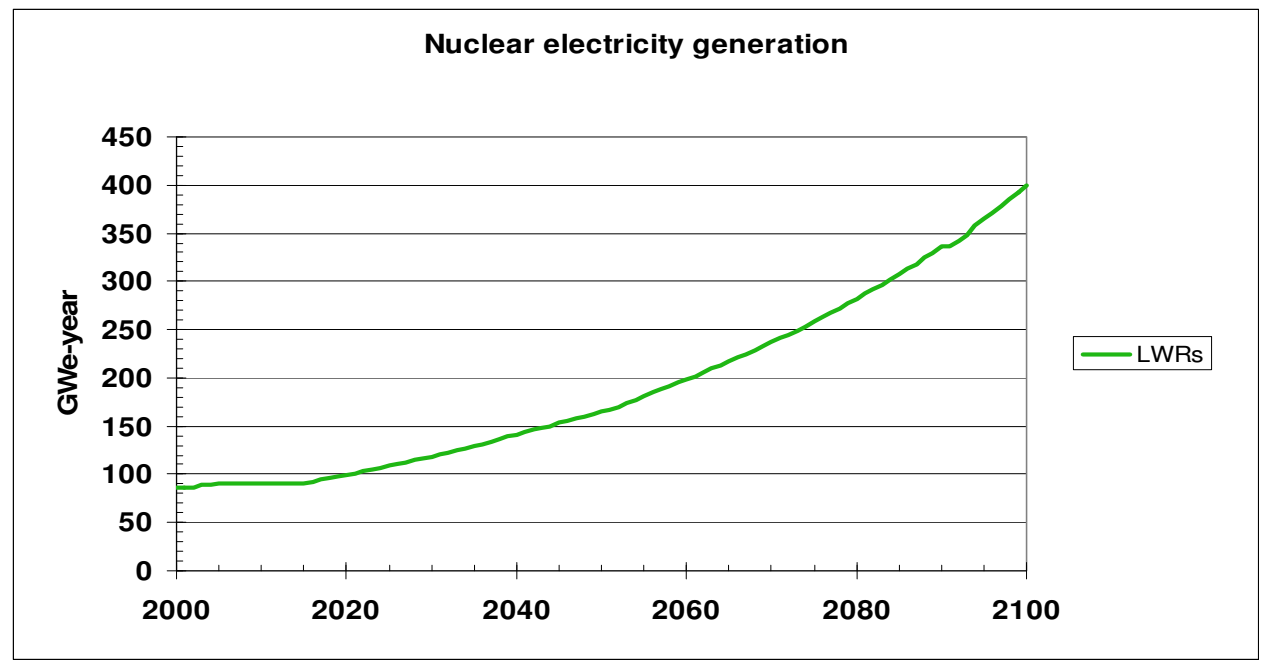

Fig. 2. Nuclear electricity generation for the once-through scenario.

\subsection{Where do the transuranics reside?}

The location of used fuel for the once-through scenario is shown in figure 3. The used fuel graph shows some used fuel in wet storage and some in dry storage. This is not reflective of actual practice, which will vary at each reactor - it instead reflects the assumption of 10 years of wet storage for cooling before used fuel is moved followed by a minimum 10 years of additional cooling storage before it is emplaced in the repository. The total cooling time from reactor discharge to repository disposal is assumed to be a minimum of 20 years, based on burnup and thermal limits for Yucca Mountain. The "additional repository inventory" reflects how much more used fuel would be available for direct disposal (cooled more than 20 years), without any assumption about where the additional repository capacity would be located. Note the decrease in dry storage between $\sim 2020$ and 2040 - this reflects excess fuel in storage today which is transferred to geologic disposal once the initial repository becomes available.

The location of used fuel is very different with the closed fuel cycle. Figure 4 shows the used fuel for the 1-tier scenario, LWR and fast reactors. The 2-tier scenario (LWR-UOX, LWRMOX, fast reactors) is very similar. When compared to figure 3, there are large differences, with the fuel previously in "additional repository inventory" now recycled. 


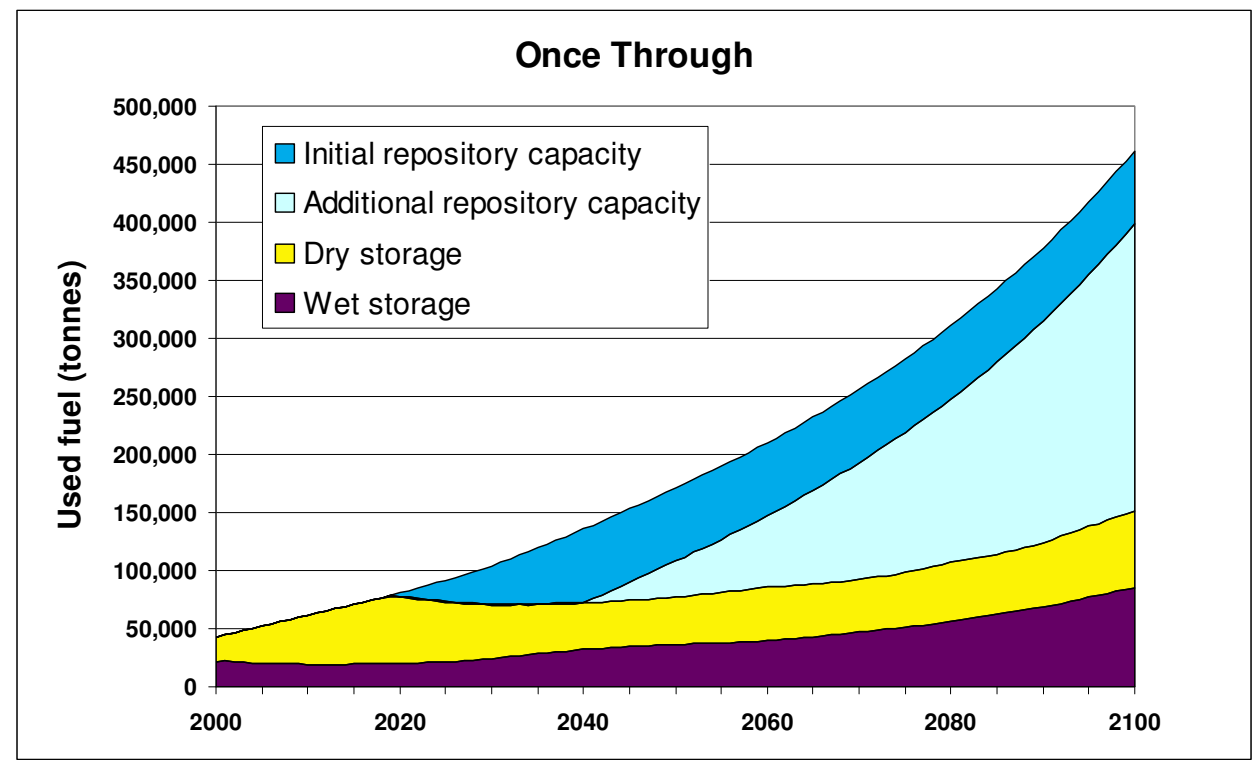

Fig. 3. Used fuel quantities and location in the once-through scenario.

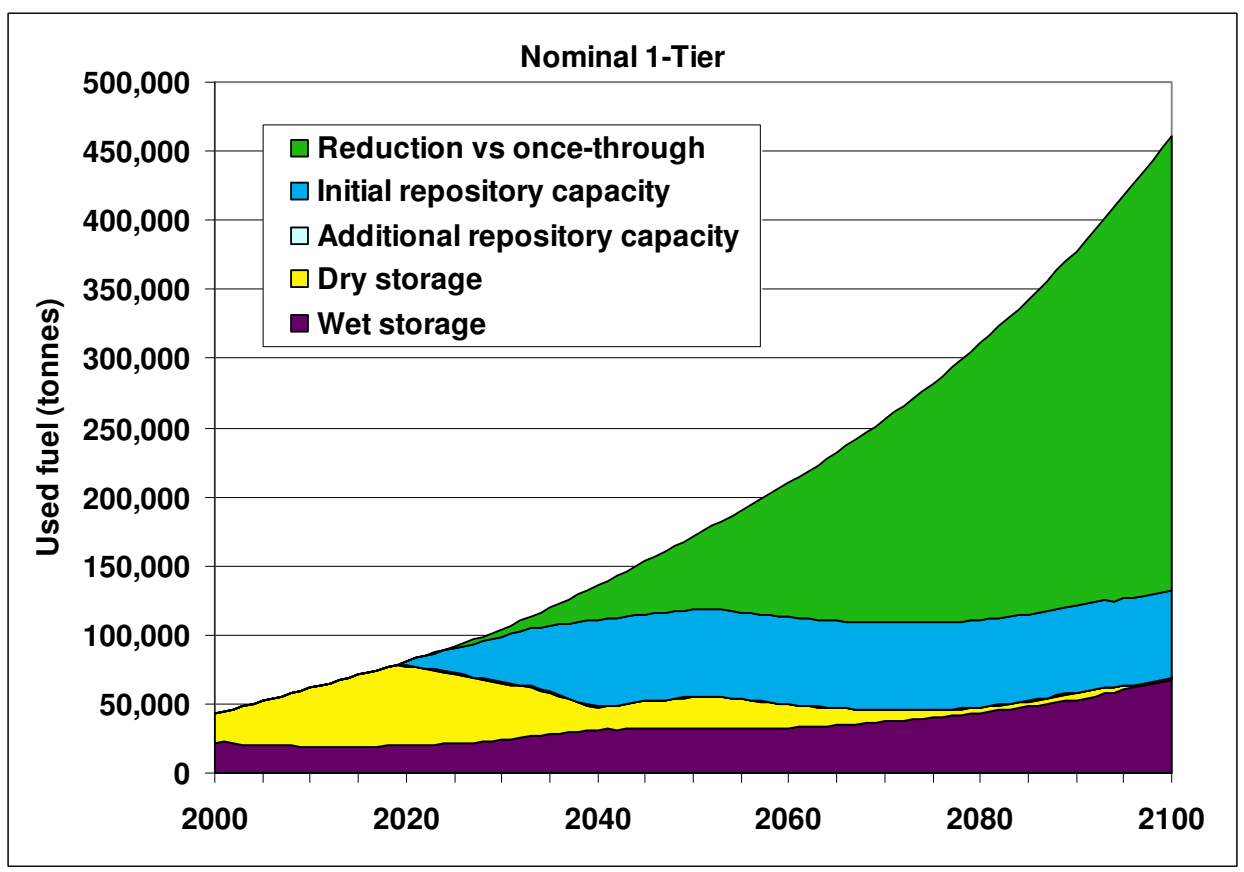

Fig. 4. Used fuel quantities and location in the 1-tier scenario. 


\subsection{How quickly new fuels and reactors penetrate the fuel cycle?}

The closed fuel cycle scenarios follow the same growth curve as shown in Figure 2, except the reactor fleet is a combination of UOX and MOX fueled LWRs or a combination of LWRs and fast reactors. Figure 5 shows electricity generation based on fuel type, with the yellow area representing the fast reactor generation and the other areas representing LWR generation using both standard UOX and MOX (in the 2-Tier scenario).
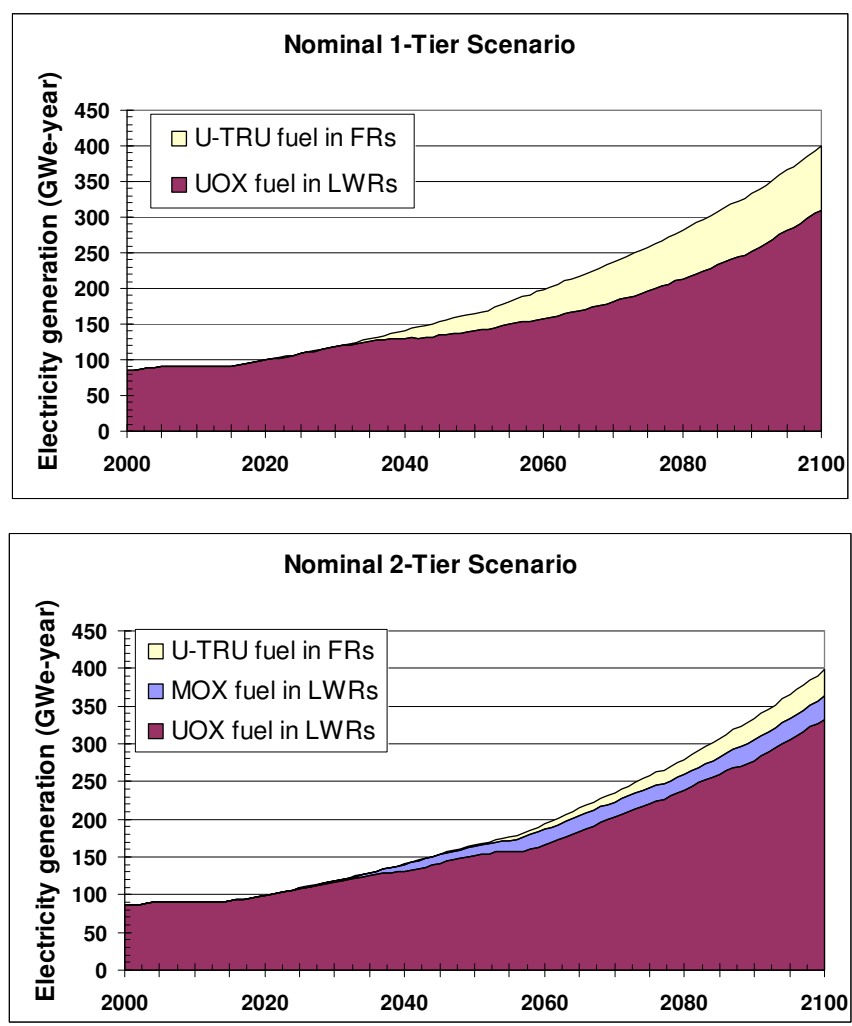

Fig. 5. Electricity generation for 1-tier and 2-tier scenarios as a function of fuel and reactor type.

Figure 6 shows the new fast reactor electricity generation projected for the closed fuel cycle scenarios, as well as the portion of total nuclear-generated electricity coming from the fast reactor fraction of the fleet. The 2-tier scenario includes fewer fast reactors and the reactors start up later due to the impact of the MOX pass in the thermal reactors. The MOX pass delays the availability of TRU for the fast reactors. The MOX pass also reduces the TRU available to the fast reactors through two mechanisms. First, some TRU is consumed in the MOX reactors - approximately two-thirds of a tonne per GWe-year. Second, the electricity produced from MOX offsets electricity from UOX, avoiding the generation of an additional quarter tonne of TRU. When these two mechanisms are combined, the amount of TRU eventually supplied to the fast reactors is reduced by almost a tonne per MOX-fueled GWeyear. 

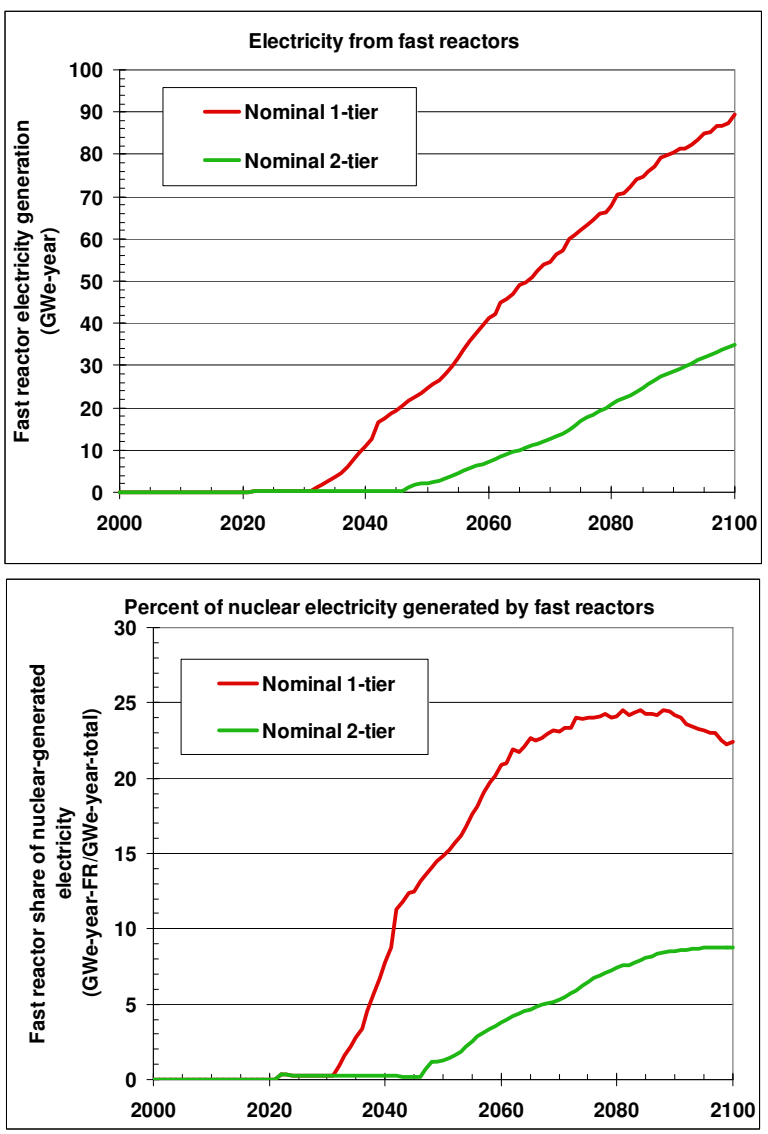

Fig. 6. Fast reactor electricity generation in absolute and percentage terms for 1-tier and 2tier scenarios.

The portion of fast reactors for the 1-tier case levels out near 25\% (and may be decreasing) as excess LWR used fuel is worked off and the fast reactors reach a dynamic equilibrium with the LWRs. This number is much lower than what is calculated by a simple static material balance (36\%). This is an important finding from the transitional analysis, as it substantially reduces the number of fast reactors required for a "balanced" system.

The difference is due to several factors:

- The amount of TRU needed to start up a fast reactor is much greater than what is needed to keep it going. This includes the first core, as well as $100 \%$ of the initial refueling needs (until used fast reactor fuel can be recycled). The static analysis assumes the fast reactors already have their initial cores and most of their refueling needs are met by recycling of their own used fuel, with only $\sim 20 \%$ coming as new makeup fuel from the LWRs.

- The fast reactors are using TRU generated at least 10 years earlier by the LWRs. While the LWR used fuel cools, more LWRs are added, so even without the startup effect the fast reactors would always be "behind". 
- Some amount of TRU is caught up in buffer storage as a hedge against temporary shutdown of the separations or fabrication facilities or the transportation links.

Several factors impact the number of fast reactors added during transition. This section uses the results of sensitivity analyses to show the relative impact of some of the more important factors. The 1-tier nominal scenario is used as the basis of analysis.

For all sensitivity runs, the same assumptions are used as for the nominal case except for the factor being examined and some associated parameters which need to be modified in tandem to keep the model in balance. For example, if a sensitivity analysis involves different values for the total nuclear growth rate, then startup dates for technologies, etc. are kept the same but the total amount of separations will be modified such that excess initial stocks of used fuel are still worked off but there is no excess separations capacity sitting idle due to a lack of feedstock.

The fast burner reactors assumed for the GNEP scenarios require TRU, including large amounts for initial startup and smaller continuing amounts as makeup for refueling. The initial core material for enough fast reactor capacity to produce 1 GWe-year of electricity includes $\sim 7$ tonnes of TRU, and additional TRU would be needed for the initial refueling cycles when $100 \%$ of the fuel would still come from used UOX. After a few years, the fast reactor fuel could be recycled and the amount of "makeup" fuel from used UOX would drop by $\sim 80 \%$. The annual makeup TRU needed for refueling the same capacity of established fast reactors would be slightly less than half a tonne. ${ }^{11}$

The source for the TRU feedstock is the LWR used fuel, which must be recycled. Assuming all available TRU is used for fast reactors, the reprocessing capacity is the single largest factor impacting fast reactor availability. (The analyses assumed that fuel fabrication was not a constraint.) In the VISION model, if there isn't sufficient TRU to start a fast reactor when a new reactor is needed, then an LWR is built instead. Fig. 7. Figure 7 shows the results of a sensitivity study on used UOX separations capacity - with lower total capacity, there are fewer fast reactors.

The separations capacity analysis is based on UOX at current burnup. Another feedstock consideration is the burnup of the used UOX. If burnup was significantly increased, many fewer tonnes of used fuel would be generated for the same level of electricity generation. However, the amount of TRU per tonne of used fuel would increase. At current burnup, the TRU content in used fuel is $\sim 1.3 \%$. If burnup could be doubled to $\sim 100 \mathrm{GWd} / \mathrm{MTiHM}$ then tonnes of used fuel discharged would be cut in half, while the TRU content per tonne would increase to $\sim 2 \%$. Thus the total amount of TRU would decreases, but the amount made available per tonne of separations capacity would increase. The isotopic makeup of the TRU also changes as burnup increases, with less fissile and more non-fissile content. This would equate to somewhat higher TRU content in the fast reactor fuel, so for the same fast reactor capacity slightly more TRU would be needed. (For the 2-tier scenario the impact of isotopic changes on Pu enrichment in MOX fuel would be greater because LWRs are more sensitive to fissile content.)

\subsection{Is growth rate important?}

Another major impact on the number of fast reactors is the overall growth rate of nuclear electricity. Higher growth equates to more used fuel, and assuming all available used UOX fuel is reprocessed, to higher numbers of fast reactors. Fig. 8. shows the impact of growth rate on both the total electricity output from fast reactors and the percent output. 

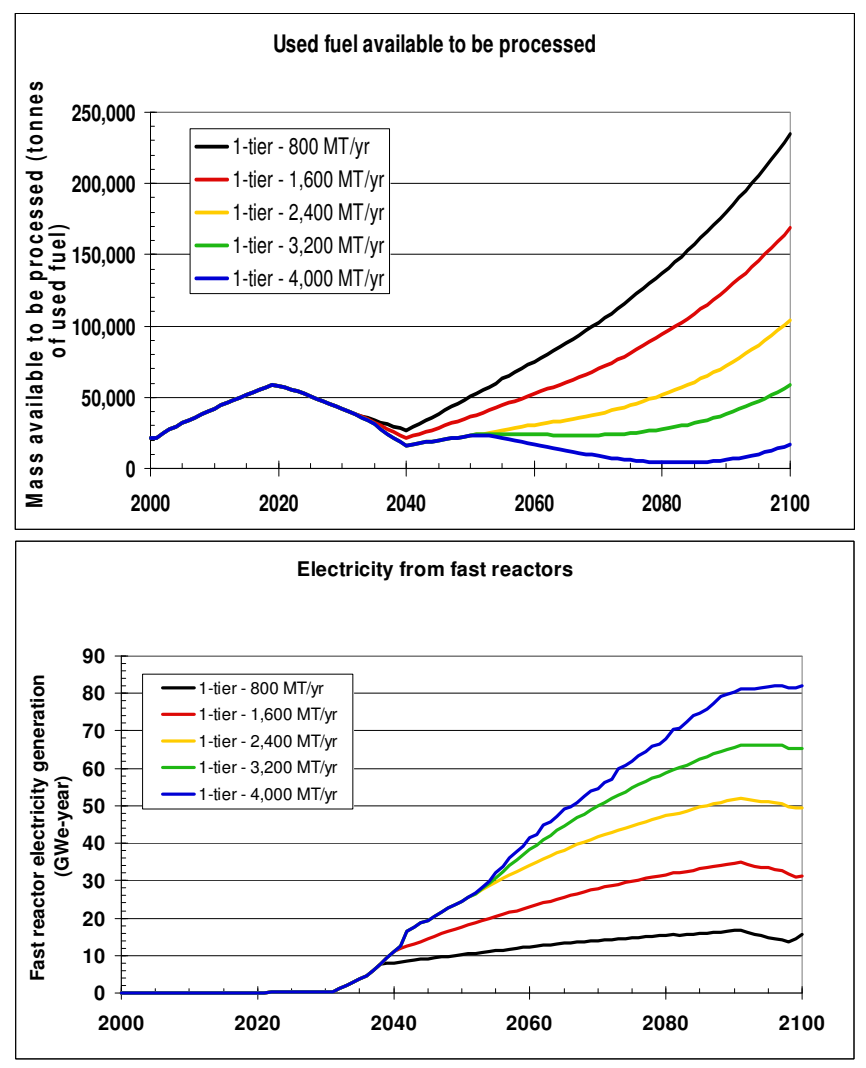

Fig. 7. Impact of varying UOX separations capacity on the amount of fast reactors.

One important finding from dynamic analysis is that as the growth rate increases the absolute level of fast reactors also increases, but the relative amount (percent of the fleet) decreases. This is primarily because the impacts of time lags increase with increasing growth rate (e.g. more LWRs are added while fuel is cooling). This finding has implications on system economics, since the cost of fast reactors is currently projected to be higher than LWRs. At low growth rates, this cost difference will have a greater impact on the overall cost competitiveness of nuclear energy versus other energy sources, but as the growth rate increases, the cost difference due to closing the fuel cycle becomes smaller.

\subsection{What is the impact of fast reactor conversion ratio?}

The TRU conversion ratio (CR) is calculated as the ratio of TRU produced to TRU consumed during fuel irradiation. Fast burner reactors are defined as having a $C R<1.0$. The $C R$ has a large impact on the level of fast reactors for two reasons:

- In the initial core, changes in conversion ratio require virtually no change in TRU content. However, in refueling there is a very large difference. At a CR of 1.0 no additional TRU would be needed, whereas in an equilibrium core at a CR of 0.0, roughly 1 tonne of makeup TRU would be required per GWe-year of generation. 
- $\quad$ Since at higher conversion ratios less makeup TRU is needed, more fast reactors can be built from the TRU provided by the LWRs. However, at a constant growth rate, more fast reactors means fewer LWRs, and less TRU generated. Thus at higher CR, while less TRU is consumed, more TRU generation is avoided (by generating electricity using recycle fuels instead of UOX).
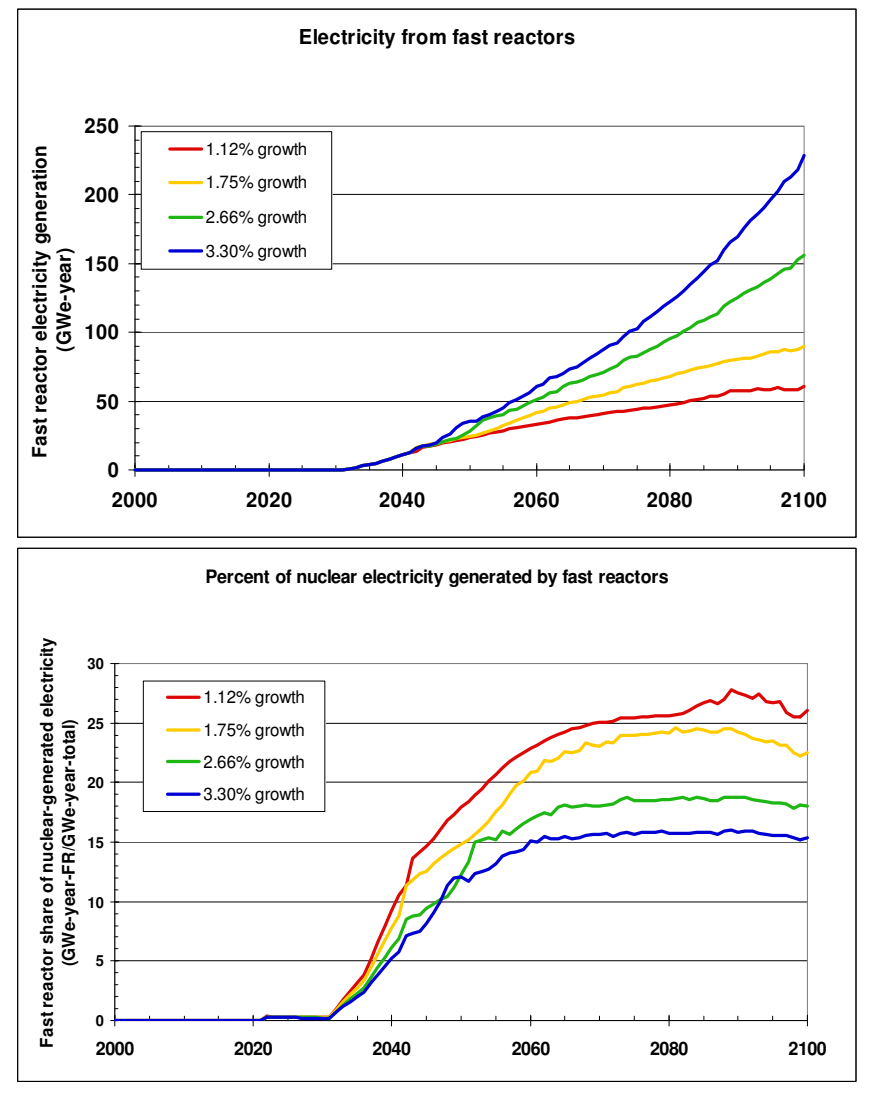

Fig. 8. Fast reactors as a function of growth rate.

Figure 9 shows the impact of conversion ratio on both the total electricity output from fast reactors and the percent output. At higher conversion ratio, both the absolute and relative level of fast reactor generation increases. The reason for this is as the conversion ratio increases, the total amount of TRU consumed plus avoided declines, so on net more TRU is available for more fast reactors.

\subsection{What is the impact of fuel cooling times?}

Used fuel cooling time is another parameter affecting feedstock availability, and therefore fast reactor capacity. The nominal cases are based on a system that is efficiently functioning by the end of the century - meaning no excess stocks of fuel at intermediate stages in the system, such as the excess fuel currently stored at reactor sites. The used fuel cooling time is 

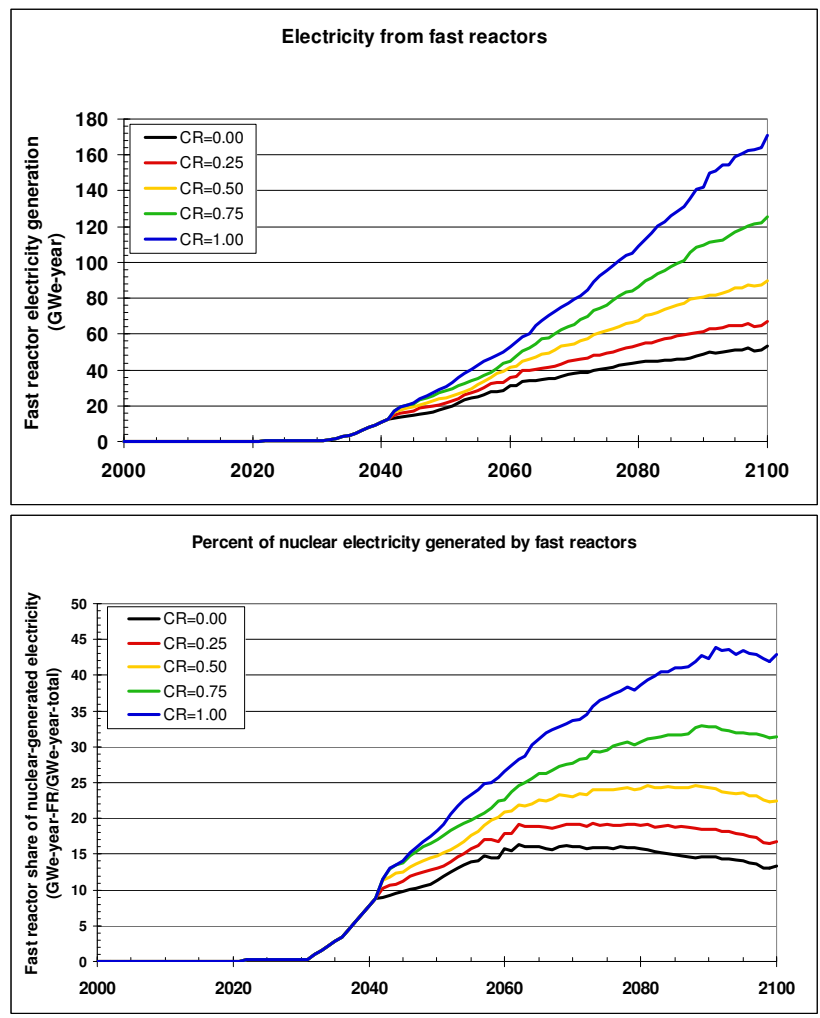

Fig. 9. Fast reactors as a function of conversion ratio.

assumed to be 10 years for LWR fuel (both UOX and MOX). This is based on the decay heat wattage limits of current shipping cask designs, which can accept full loads of used fuel at current burnup approximately 6 or more years after discharge. The value was rounded up, both to account for potential higher burnup and for MOX fuel. However, an "efficiently functioning" system could also be defined with longer cooling times. This would mean more TRU would be tied up in used fuel not yet available for reprocessing, and therefore fewer fast reactors.

Cooling time for fast reactor used fuel is a much larger factor than cooling time for LWR used fuel in determining the number of fast reactors deployed. The nominal case assumes on-site recycling of fast reactor fuel, which means it does not need to cool sufficiently for efficient shipping. For this reason, the assumed cooling time is only 1 year. (An additional year is assumed for separations and fuel fabrication; resulting in 2 years total recycle time.) One alternative is regional or centralized reprocessing of fast reactor fuel. A number of factors may lead to centralized facilities, including economies of scale and fuel type. However, significant transportation considerations must also be considered.

Centralized reprocessing is more likely if an aqueous technology is used, because this technology has significant economies of scale. The overall plant complexity stays fairly constant with size, while the lines, tanks, and other equipment scale up. If an electrochemical (Echem) process is used, there is not as significant a gain in scale economies. 
Echem is essentially a batch process with limits on equipment size, so a larger plant would involve more processing stations, and therefore more equipment and complexity. Aqueous processing is usually equated with oxide fuels and Echem with metal fuels - both fuels have been used successfully in fast test reactors. A decision on fuel type for the initial fast reactor has not yet been made, as more information is needed.

Fast reactor fuel produces higher levels of decay heat per MTiHM than LWR UOX fuel. The fresh fuel has a high percentage of TRU, including plutonium-238 (Pu-238), americium-241 (Am-241) and curium-244 (Cm-244). Used fuel has large percentages of both TRU and fission products (due to much higher burnup than UOX). The fuel also contains heavy isotopes with high energy decay products, requiring substantial shielding. These properties of fast reactor fuel make shipping more difficult, and longer cooling times or less fuel per shipment may be required.

Figure 10 shows the impact of fast reactor fuel cooling time on the fraction of fast reactors at the end of the century. The impact of fuel type is also shown - oxide fuel has a softer spectrum, allowing for longer fuel cycles but also requiring more TRU to support those cycles, and therefore more initial TRU for startup. However, overall impact of fuel type is minimal when compared to the impact of cooling time.
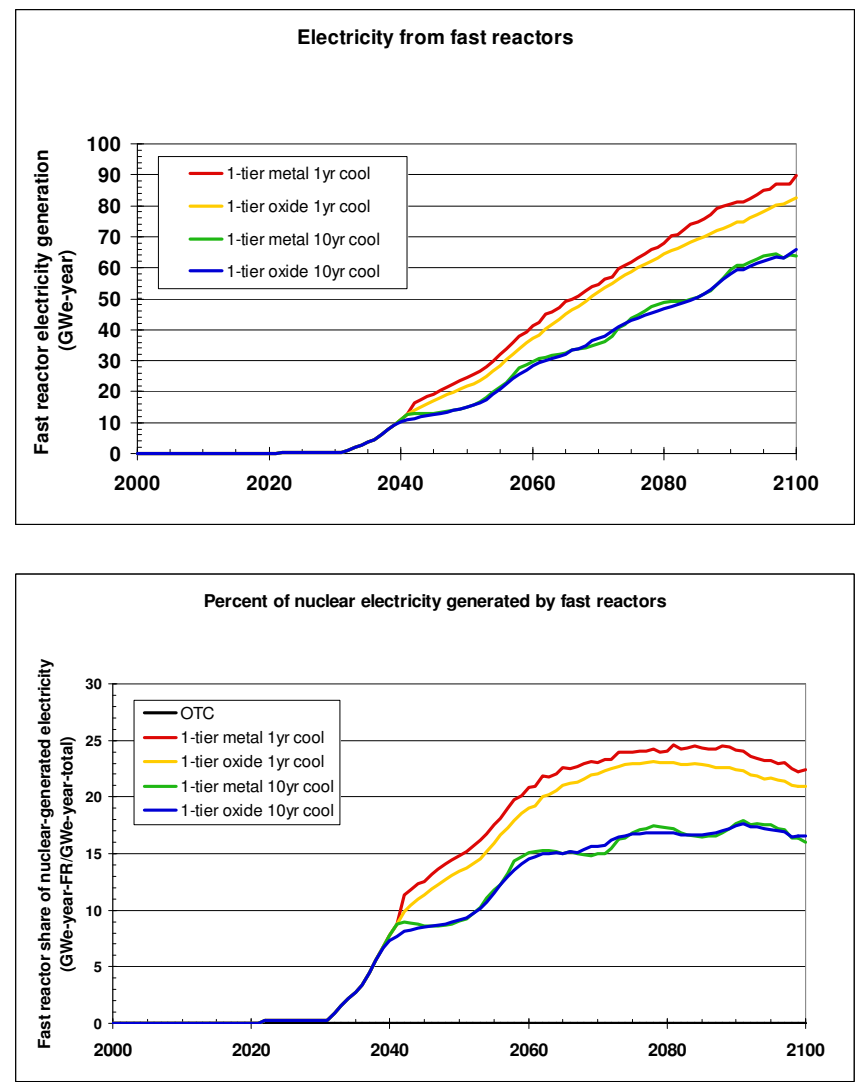

Fig. 10. Impact of cooling time and fuel type on fast reactor level. 


\subsection{What is the impact of delaying implementation of fast reactors?}

The final factor considered in determining the level of fast reactors is the time of introduction of the technology. The 2-tier case has the effect of delaying fast reactor introduction by $\sim 15$ years due to the delay in TRU becoming available for fast reactors while it is in the MOX cycle. But the timing of fast reactor introduction could also be later for the 1tier case. Figure 11 shows the impact of delaying fast reactor introduction by 5,10 and 15 years, while including the nominal 2-tier case for comparison.
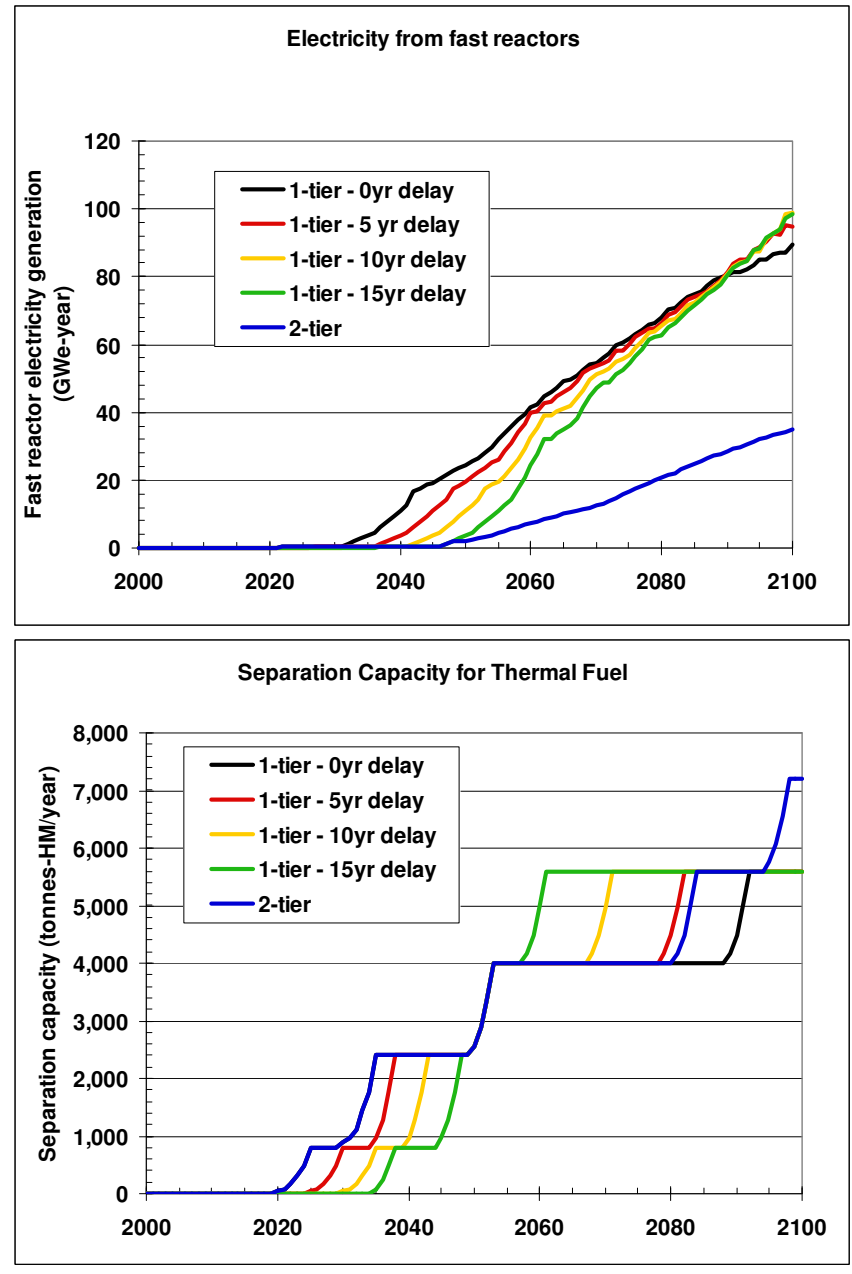

Fig. 11. Impact of delayed fast reactor introduction.

Delaying fast reactor introduction has little long-term impact on the numbers of fast reactors. In fact, there are more fast reactors toward the end of the century than in the nominal scenario. This is due to more TRU being generated by LWRs in the middle of the century (less TRU avoided), providing more feedstock. While initial separations is delayed 
(because there are no fast reactors to take the separated TRU), the final separations capacity must be brought on line sooner to achieve the elimination of excess used fuel by 2100 . Stores of cooled fuel are twice to three times as high throughout much of the century.

\section{Lessons from dynamic analyses}

Fuel cycle system analyses can be either static or dynamic; they each have value. Static equilibria are easier to calculate, to understand, and to use to compare options. By static equilibria, we mean the system is not changing. For example, static equilibria can include constant time lags for used fuel cooling but not technology changes, deployment, displacement, etc. Dynamic simulations are more realistic. ${ }^{17}$ The 2005 AFCI objectives provided to Congress ${ }^{1}$ and recent U.S. comparisons ${ }^{2,3}$ are primarily static in nature.

Consider three examples of the differences between static and dynamic. First, assume in fast reactors that zirconium (fast reactor metal fuel alloy) and steel (fast reactor metal fuel cladding) are recycled. At static equilibrium, the only required makeup zirconium and steel would be the small amount required to balance processing losses. However, in a dynamic analysis with increasing numbers of fast reactors, zirconium and steel would be required to supply the new fast reactors. The amount of makeup material required would increase as either the growth rate or recycle time lag from fuel fabrication back around to new fuel fabrication increase.

The second example is system evolution. A static equilibrium analysis tells us little about how to manage the system; or, how the system can evolve from one strategy to another. A dynamic analysis or simulation provides some insights into the sequencing of events. Understanding the true system evolution requires a fully time dependent calculation, as provided by system analysis models such as VISION. Under some circumstances, a system establishes a "dynamic equilibrium" in which the relative relationship among parts of the system is fairly constant, but the entire system continues to grow.

The third example is economics. A static equilibrium is appropriate when discount rates, the time value of money, and cash flows are not addressed. If the time value of money is accounted for, then cash flows that lead others are given greater weight; cash flows that lag others are given less weight.

\subsection{Deployment}

All advanced fuel cycles require separation of used UOX fuel. All simulation results depend not only on when the first UOX separation plant starts, but also its capacity. In the simulations presented here, the first separation plant starts in 2020 at 800 tonnes-iHM/yr. It also matters how soon a second UOX separation plant might be deployable. In these simulations, the second plant starts in 2030 at 1600 tonnes-iHM/yr. Consider that the U.S. is currently accumulating used UOX at $\sim 2000$ tonnes-iHM/yr and there are few proposals that the first UOX plant be that large. So, just to build capacity equal to the anticipated UOX discharge rate in 2020-2030, multiple separation plants will be required and simulation results depend on how soon that is possible.

All advanced fuel cycles require new fuels that recycle some or all of the transuranic material. Many options require new types of reactors. In most simulations, commercial fast reactor deployment starts in 2032 (1-tier) or 2047 (2-tier). Simulation results also depend on how soon new technologies can be deployed, not just when deployment starts. For example, 
many of the calculations in this report constrain fast reactor deployment to 1 GWe of capacity/yr for 5 years, followed by 2 GWe/yr for 5 years. MOX or fast reactor deployment is also constrained by availability of recycled material, which is in turn constrained by deployment of UOX separation capacity. Reactor deployment can also be constrained in low nuclear growth scenarios because new reactors are not built until existing reactors retire. This growth constraint does not occur at $1.75 \% / \mathrm{yr}$ growth assumed in most of the calculations. Many of the same reactor deployment constraints would hold for fuel fabrication capacity but in the current simulations fuel fabrication capacity was not constrained.

Changes in fuel cycle technology combinations (reactors, fuels, separation, waste forms, waste disposal sites) take decades to be significantly manifest in system-level parameters such as uranium utilization or used fuel inventories in wet storage. That is, the fuel cycle has long response times. Reasons include new technologies take decades to deploy and it can take a decade for fuel to go once around the recycle loop.

The sequence of deployment of new fuel cycle technologies is generally constrained. An obvious example is that MOX fuel in LWRs cannot occur before LWR UOX separation begins. Proper sequencing of technology and facility deployments is a contributor to the long response times.

The adaptability, resilience, and robustness (versus fragility) of fuel cycle options vary. For example, LWRs with MOX are robust in the sense that if MOX fuel is unavailable, one can use enriched UOX without hesitation; enriched UOX fuel is typically assumed to be a "commodity" without dependence on unique facilities. A burner fast reactor is "fragile" in that it requires separated TRU for both startup and throughout its operating life, making it dependent on sources of used fuel, separation of that used fuel, and fabrication of new fuel which are likely to each be unique facilities that must be deployed in sequence and matched in capacity size to avoid choke points and excessive stockpiles. The adaptability of new reactors is enhanced (at a cost) to the extent that multiple fuel types or fuel compositions are considered in reactor design and licensing, e.g., LWR UOX versus MOX or varying conversion ratio fast reactors.

\subsection{Waste management}

Our first observation is that one way to reduce waste burden is not to make the waste. Reactors fueled with enriched uranium are net producers of TRU (TRU CR>1), ${ }^{1}$ while reactors fueled with recycled TRU may be net producers $(C R>1)$ or consumers $(C R<1)$. Fig. 12 shows the reduction of TRU inventory this century as a function of fast reactor TRU CR for 1-tier dynamic simulations. TRU reduction occurs for two reasons; one is consumption of TRU in fast reactors. (In other simulations, TRU is consumed in thermal reactors.) The other is avoidance of TRU production by displacing reactors with net TRU

\footnotetext{
1The TRU conversion ratio is TRU production/destruction. $C R=1$ means the output TRU content equals the input TRU content. Systems with uranium fuel thus create TRU. For systems operating with TRU fuel, the TRU CR is often numerical similar to the fissile breeding ratio as U238 (non-TRU, fertile) is converted to TRU, which is mostly fissile. Indeed, as the TRU CR increases, it approaches the fissile breeding ratio as a higher fraction of the produced TRU is Pu239, which is fissile. As an example of the difference between TRU conservation ratio and fissile breeding ratio, note that conversion of Pu240 to Pu241 does not impact the TRU conversion ratio but does impact fissile breeding ratio. The AFCI program tended to use TRU conversion ratio rather than fissile breeding ratio as relatively more indicative of waste management and proliferation resistance/physical protection issues.
} 
production (such as LWR-UOX) with other reactors and fuels. As an example, a CR=1 fast reactor is not a net consumer of TRU; but the more electricity generated by such reactors, the less that must be generated by LWR-UOX and therefore significant TRU production is avoided.

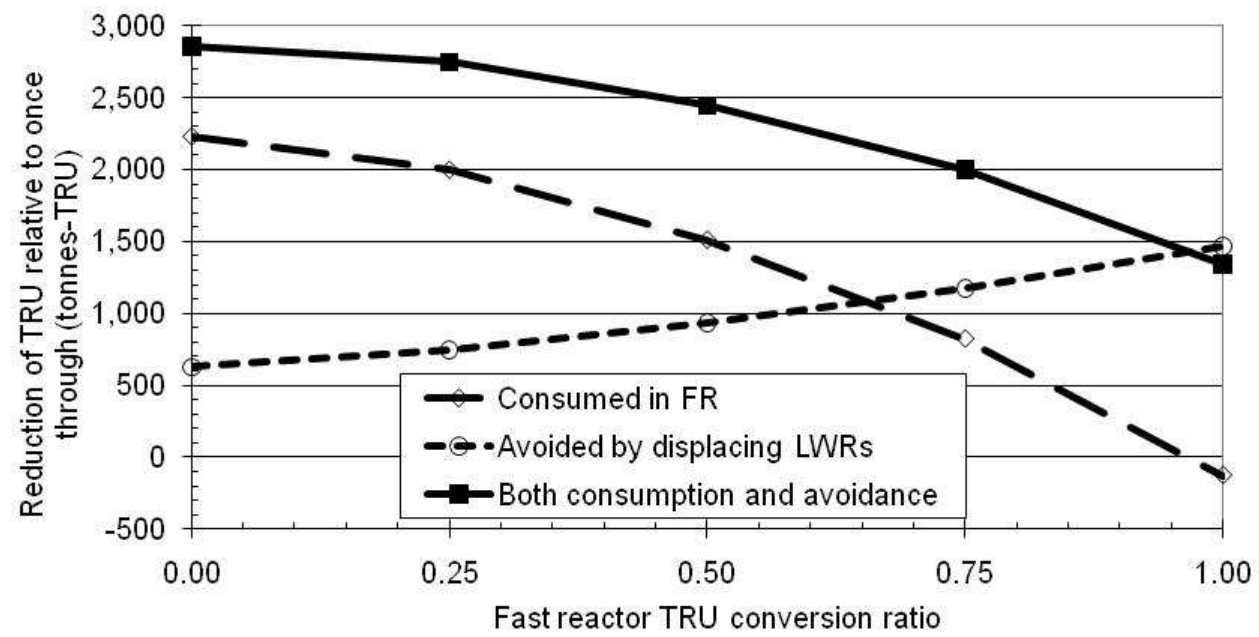

Fig. 12. Consumption and avoidance of TRU, both reduce TRU inventories.

Below $C R=1$, there is more uranium recovered from separation of used fuel ("recovered uranium") than used; it goes into storage. Similarly, uranium depleted by enrichment ("depleted uranium") is not used and goes to storage. Above $C R=1$, both recovered uranium and depleted uranium is eventually used. In the analyses and results presented below, for $\mathrm{CR}<1$; RU and DU are considered in storage and are not included in either the active or waste inventories.

Below $C R=1$, the introduction of fast reactors does not increase the production of TRU this century relative to the once through fuel cycle. This cross-over point between increasing versus decreasing TRU this century depends on many parameters, notably the nuclear power growth rate. In all cases, it takes a CR significantly greater than one before there is a net TRU production by the fleet this century.

The second waste management observation is that the radiotoxicity results depend strongly on which transuranics are recycled, processing loss rates, and the time at which radiotoxicity is to be evaluated. Individual isotopes vary as to their contribution (per mass) to radiotoxicity. Consider the example in fig. 13. It shows that if UOX-51 is not recycled or if only uranium from UOX-51 is recycled; the radiotoxicity stays above natural uranium ore until $\sim 300,000$ years; there is no reduction in the radiotoxicity source term. If $99 \%$ to $100 \%$ of the uranium and plutonium are recycled, the radiotoxicity remains above natural uranium ore until 10,000 to 20,000 years; a reduction of LTR-1000 by factors of 7.9 to 8.5 . U and Pu constitute $94.6 \%$ of used UOX-51 or $99.89 \%$ of the heavy metal in used UOX-51. (Of used UOX-51, $0.1 \%$ is minor actinides and $5.3 \%$ is fission products.) If $99 \% / 99.5 \% / 99.9 \% / 100 \%$ of uranium, neptunium, plutonium, americium, curium, and californium are recycled, the LTR-1000 is reduced by factors of $100 / 200 / 950 / 20000$; and the time to reach uranium ore 
drops to $2000 / 700 / 400 / 300$ years. A recent NEA study ${ }^{17}$ shows similar trends. At very long times, even the longest-lived minor actinides decay into uranium isotopes and their progeny so that the two "no MA recycled" curves actually increase back toward 1.0 (natural uranium) as the uranium progeny isotopes such as Po210 grow in.

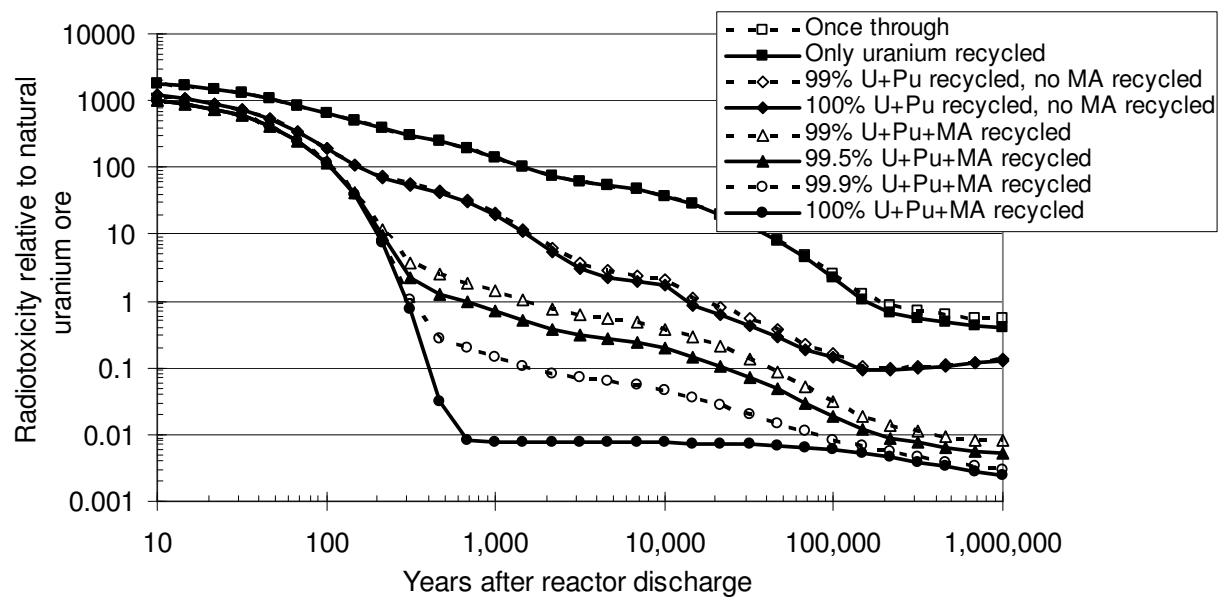

Fig. 13. Radiotoxicity of residual waste from 5-year old UOX-51 as function of minor actinide (MA) recycling.

The third waste management observation is that significant material accumulates throughout the system during recycling; thus, achievement of high waste management benefits depends on continuation of recycling. Don't stop!

The metric is the long-term decay heat emitted by material from 50 to 1500 years; this is a rough approximation of the long-term thermal response in a repository. ${ }^{18}$ It is the same concept as the "decay heat integral". ${ }^{17}$ We call it a "commitment" because once emplaced, the energy that will be deposited has been committed; this is analogous to the concept of "dose commitment"; radioactivity taken into the human body commits the body to receiving a dose integrated over time. The heat units are energy (GWth-yr), heat rate (GWth) integrated over time (years). Figure 14 shows the heat commitment in a 1 -tier $C R=0.50$ case. The heat commitment in 2100 would be 86 GWth-yr with the once through fuel cycle; adoption of 1-tier $C R=0.50$ recycling reduces that to $47 \mathrm{GWth}-\mathrm{yr}$. So, if recycling were to stop in 2100 and all the material in the system went to a repository, the heat-commitment improvement factor to the repository would be only $1.8=86 / 47$.

Relative to used fuel and HLW, there is nil heat commitment in depleted uranium (DU), recovered uranium (RU), low-level waste (LLW), or even TRU waste. (There is little TRU waste in these scenarios; virtually all TRU-containing waste is considered HLW.) But, there is $7 \mathrm{GWth}-\mathrm{yr}$ in decay heat storage (CsSr). So, if recycling were to stop in 2100 and that material were not sent to a repository, the improvement factor would increase from 1.8 to $2.1=86 /(47-7)$.

If recycling continues beyond 2100, the 39 GWth-yr active material in the system (reactor, wet storage, separation, fabrication) and 0.8 GWth-yr in dry storage avoid going to the repository. The repository only has 0.2 GWth-yr, so the maximum improvement factor 
could approach $430=86 / 0.2$; this is an overestimate because some of the 40 GWth-yr (active, dry) will end up in the repository as recycling continues.

Consider if the material in decay storage is sent to a repository. Then, the repository heat commitment is 7.2 GWth-yr instead of 0.2 GWth-yr and the maximum improvement factor, even if recycling continues, would be $86 / 7.2=12$. Again, this is an overestimate because some of the $40 \mathrm{GWth}-\mathrm{yr}$ in active systems would eventually go to the repository.

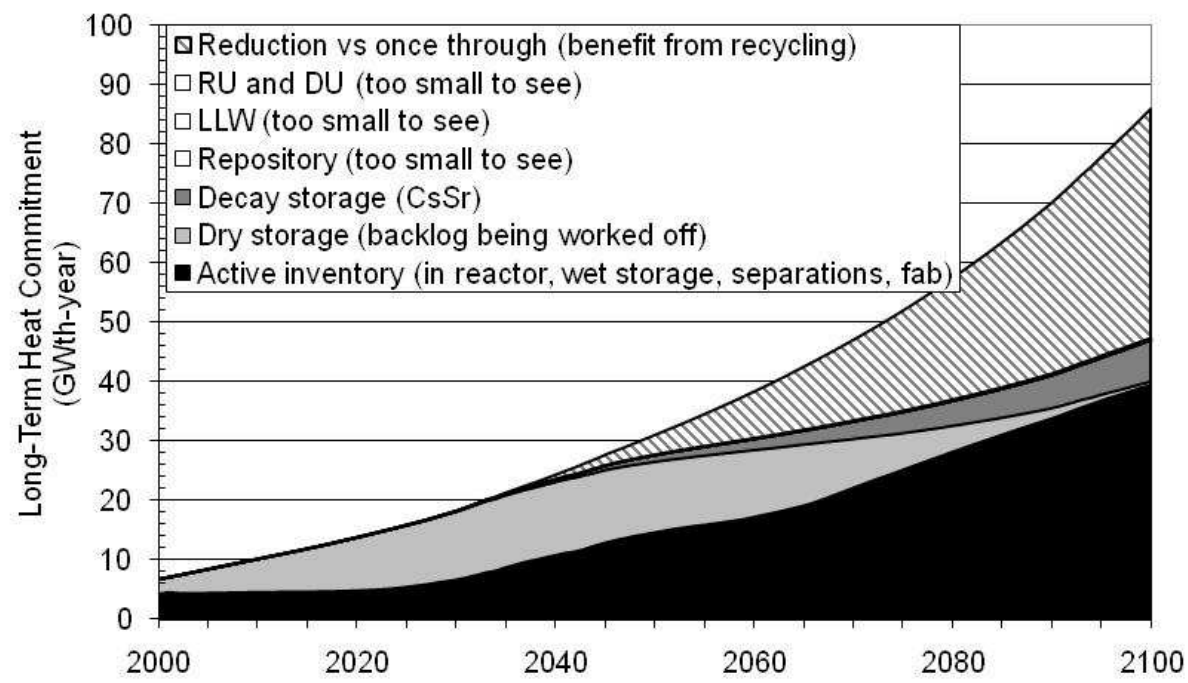

Fig. 14. Long-term heat commitment for 1 -tier $C R=0.50$ fast reactor case.

So, achieving high improvements in repository heat commitment requires continuation of recycling, recycle of $\mathrm{Pu}$ and $\mathrm{MA}$, and use of decay storage for CsSr.

The fourth observation is that uranium dominates the mass of the system. Figure 15 shows the composition of the mass in the system for a 1-tier case over the simulation time. The mass at the end of the simulation is dominated by DU and RU; the mass of fuel products and total waste is small. This case uses $C R=0.50$ fast reactors. To help understand this, consider the static equilibrium in figure 16 . At $C R=0.50$ only $1.3 \%$ of the RU and none of the DU is used as fuel. (Uranium in discharged fast reactor fuel is assumed recycled into new fast reactor fuel.) Use of $R U$ increases to $4.2 \%$ at fast reactor $C R=0.75$. At $C R=0.986$, all of the RU is used but only some of the DU is used. Above TRU CR $=0.9985$, all of the RU and DU is used as fuel (other than processing losses). Dynamic simulations show somewhat worse results than figure 15 because of the time lags involved in building and operating fast reactors in a growing system, i.e., LWRs are built first and their TRU is used to fuel later fast reactors.

The final waste management observation is that one must put TRU "in play" in order to reduce waste burdens. Use it to lose it. TRU that is sitting in storage does not help reduce waste burdens, except in so far as high-heat load isotopes decay; the notable example is Cs137 and Sr90 with 30-year half-lives. Similarly, the holdup of transuranic material in the system impacts system performance so that short time lags, e.g., when facilities are colocated instead of at different locations, can lead to faster waste management benefits via 
consumption and avoidance of TRU at a given TRU CR. Certainly the rate of TRU consumption from the standpoint of an individual reactor depends on the reactor power and CR; however, from the standpoint of the entire fleet, the rate of TRU consumption and avoidance additionally depends on how fast TRU-consuming reactors (burner FR in this instance) displace TRU-producing reactors (LWRs in this instance), how quickly discharged fuel can be separated and recycled material re-inserted into reactors. Figure 17 shows the impact of increasing the "wet" storage time from 1 to 10 years for a 1 -tier $C R=0.50$ fast reactor case, approximating a shift from onsite to offsite separation and fuel fabrication. The total time from reactor discharge to reinsertion changes from 2 to 11 years.

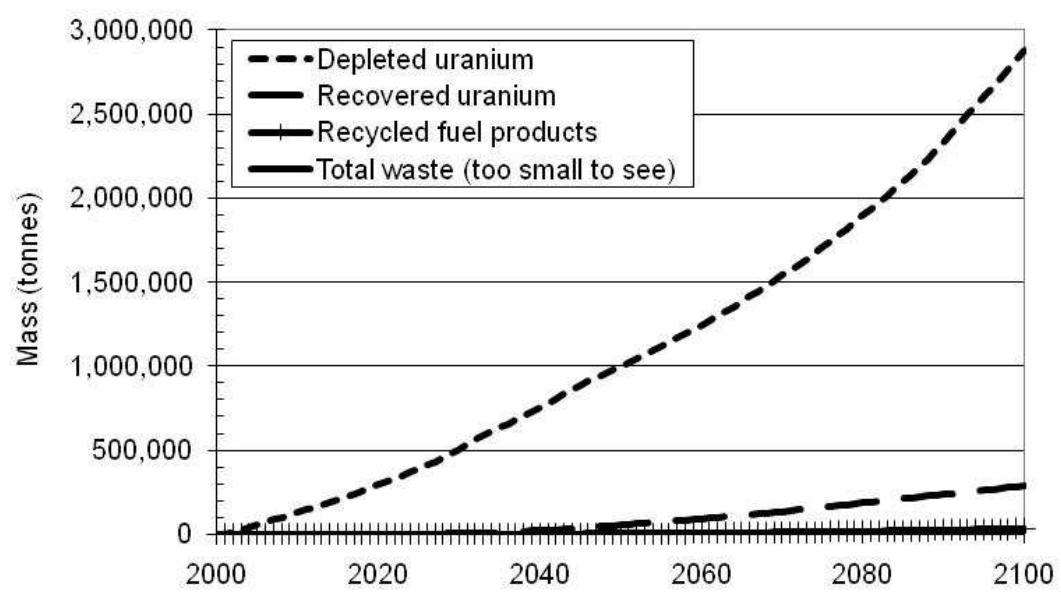

Fig. 15. Waste, uranium, and fuel product mass for a 1-tier recycle case, $C R=0.50$ fast reactors, no packaging included.

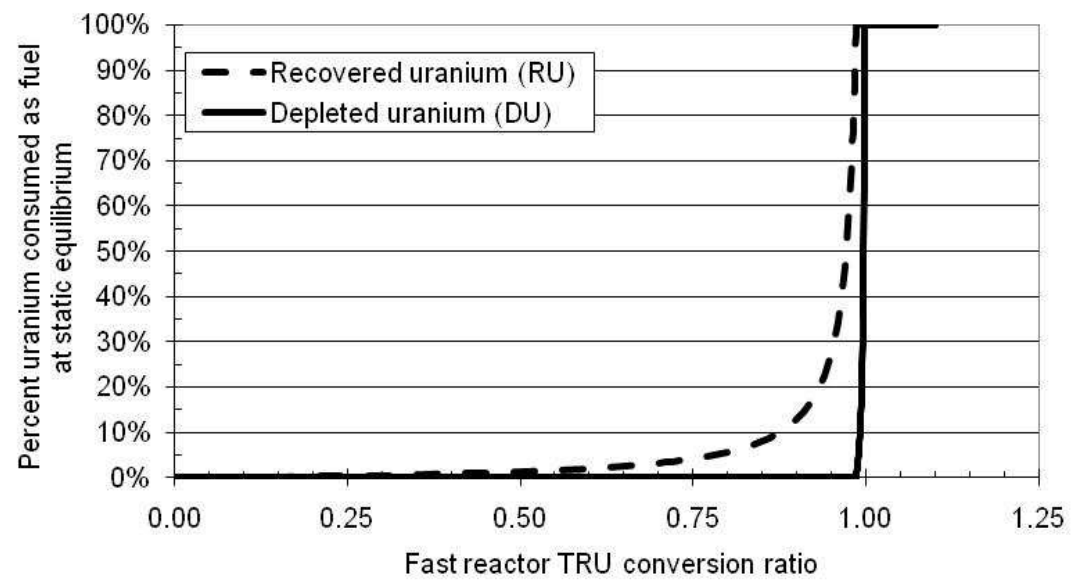

Fig. 16. Percent of RU and DU from LWRs used as fast reactor fuel with fast reactors and LWRs in static equilibrium. 


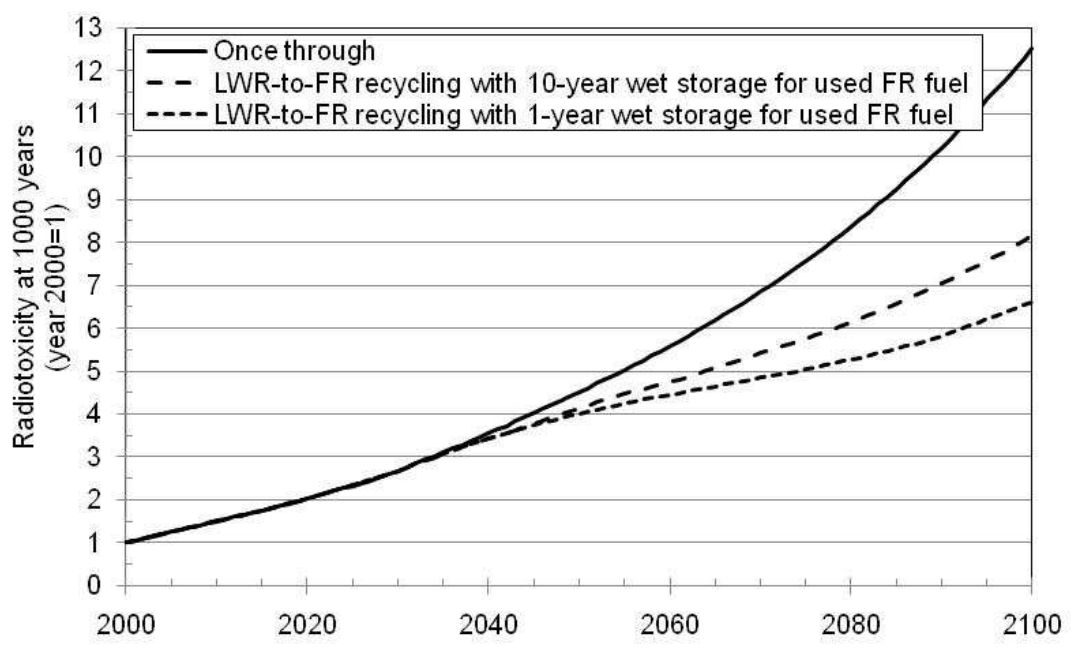

Fig. 17. Long-term radiotoxicity of 1 -tier fast reactor $C R=0.50$ with either 1 or 10 year "wet" cooling before a year of separation and fuel fabrication.

\subsection{Uranium utilization}

To start, consider the range of estimates of world uranium resources in Table II relative to the 2006 production rate of 40,000 tonne-U.19 The current nuclear power production rate would exhaust total estimated conventional resources $(16,000,000$ tonnes-U) in 400 years. That time scale can drop to within a century with modest nuclear power growth, but extend many centuries if unconventional resources become practical.

\begin{tabular}{|c|c|c|}
\hline Conventional resources & Reference & Tonnes-U \\
\hline Reasonably assured resource, $<\$ 130 / \mathrm{kg}-\mathrm{U}$ & Redbook $^{19}$ & $3.3 \mathrm{e} 6$ \\
\hline Inferred resources, $<\$ 130 / \mathrm{kg}-\mathrm{U}$ & Redbook $^{19}$ & $2.1 \mathrm{e} 6$ \\
\hline Prognosticated resources, $<\$ 130 / \mathrm{kg}-\mathrm{U}$ & Redbook $^{19}$ & $2.8 \mathrm{e} 6$ \\
\hline Speculative resources, $<\$ 130 / \mathrm{kg}-\mathrm{U}$ & Redbook $^{19}$ & $4.8 \mathrm{e} 6$ \\
\hline Total estimated conventional resources & & \\
\hline Above 4 categories, $<\$ 130 / \mathrm{kg}-\mathrm{U}$ & Redbook ${ }^{19}$ & $1.3 \mathrm{e} 7$ \\
\hline Above 4 categories, plus "cost range unassigned" & Redbook $^{19}$ & $1.6 \mathrm{e} 7$ \\
\hline Undiscovered + known, $<\$ 130 / \mathrm{kg}-\mathrm{U}$ & Herring 20 & $1.5 \mathrm{e} 7$ \\
\hline Undiscovered + known, $<\$ 130 / \mathrm{kg}-\mathrm{U}$ & Steyn ${ }^{21}$ & $1.6 \mathrm{e} 7$ \\
\hline Unconventional resources & Reference & Tonnes-U \\
\hline Uranium in sandstone deposits & Herring 20 & $1.8 \mathrm{e} 8$ \\
\hline Uranium in volcanic deposits & Herring 20 & $2.0 \mathrm{e} 9$ \\
\hline Uranium from seawater & Herring 20 & $4.2 \mathrm{e} 9$ \\
\hline Uranium in phosphate deposits & Herring 20 & 8.0e11 \\
\hline
\end{tabular}

Table 2. World Potential Uranium Resources 
Nuclear fuel isotopes are either fissile or fertile; fissile isotopes are much more readily consumed. The only fissile isotope in nature is U-235, which is $0.7 \%$ of uranium ore. The only fertile isotopes in nature are U-238 (99.3\% of uranium ore) and Th-232 (100\% of thorium ore). To extend ore utilization substantially above $0.7 \%$, one must convert or "breed" fertile to fissile isotopes. Fertile U-238 can be bred to fissile Pu-239, called the uranium-plutonium fuel cycle (or plutonium for short). Fertile Th-232 can be converted to fissile U-233, called the thorium-uranium fuel cycle (or thorium for short). The ratio of producing fissile isotopes (from fertile) to consuming fissile isotopes is called the fissile breeding ratio. A ratio greater than 1 means that more fissile isotopes are bred than consumed, shifting the limiting resource from fissile isotopes to fertile isotopes.

All current U.S. reactors have fissile breeding ratio less than 1 and thus use less than $1 \%$ of the original uranium ore. Recycling in such reactors is not sufficient to break $1 \%$ because their fissile breeding ratios remain below 1 . When the fissile breeding ratio is greater than 1 , the uranium (or thorium) utilization can exceed 1\%. There are exotic concepts in which maximize in-situ breeding without recycling used fuel, it advanced materials can be developed, these may achieve $\sim 10 \%$ uranium utilization. With recycling of used fuel in breeder reactors, uranium and thorium utilization can approach $100 \%$, subject to processing losses.

Accomplishing 50-100x improvement in uranium utilization means near total replacement of LWRs (or other thermal reactors) with fast reactors. For example, if $10 \%$ of the reactor fleet remains LWRs with UOX fuel with $90 \%$ of the electricity from fast breeder reactors, the maximum uranium utilization improvement is 10x. Such substantial infrastructure change from LWRs to FRs is notoriously difficult. ${ }^{22}$ As most of the U.S. LWR fleet is moving toward a 60-year reactor lifetime, such a replacement of LWRs will take at least 6 decades from the operation of the last LWR. As an example, if fast breeder reactor deployment requires 2 decades from first deployment to $100 \%$ of new construction (i.e. allowing 2 decades for industrial scale-up and market penetration); it will be 2120 before the last LWR retires. Predicting uranium resources so far in advance is questionable.

The above example assumes that the fast breeder reactors can grow faster than nuclear power growth during its market penetration from 0 to $100 \%$, followed by continued breeder growth at the nuclear power growth rate once it reaches $100 \%$ of new construction. The rate of breeder deployment is constrained by fuel supply, which we have tended to assume is transuranic material recycled from LWRs and fast reactors once operating, rather than high enriched uranium ( $30 \%$ U235).

We have derived the required TRU conversion ratio, such that LWR are not required to supply TRU to a growing fleet of fast reactors:

$$
C R=e^{m\left(t_{F}+t_{R}\right)}
$$

where $m$ is the growth rate; $t_{F}$ is the time for cooling, separation, and fuel fabrication; $t_{R}$ is the time in reactor. Thus, $t_{F}+t_{R}$ is the total turnaround time. As an example, if $m=0$, then $C R=1$ and the system is in balance with no LWRs. Or, if one wants $m>0$, then $C R>1$. The higher the desired growth rate, the higher the required CR.

In addition, because new fast reactors (growing at rate $m$ ) must have $t_{R}-1$ additional years' worth of fuel to start up, equation 1 must be multiplied by another term. ${ }^{2}$

${ }^{2} \mathrm{~A}$ core contains $t_{R}$ years worth of fuel, with 1 year's worth added each year. At startup, there is therefore an extra $t_{\mathrm{R}}-1$ that must be provided. 


$$
C R=e^{m\left(t_{F}+t_{R}\right)}\left(1+m\left(t_{R}-1\right)\right)
$$

At a nominal growth rate of $1.75 \% / y r$, the time lags in the system are important. If $t_{F}=2$ (example for onsite recycling) and $t_{R}=4$, then $C R=1.17$ is required. If $t_{F}=11$ (example for offsite recycling) and $t_{R}=4$, then $C R=1.36$ is required.

Fig. 18 shows the required $C R$ as function of desired growth rate and turnaround time. The minimum turnaround time is probably $\sim 5$ years (1-year cooling, separation, fabrication and 4 years in reactor).

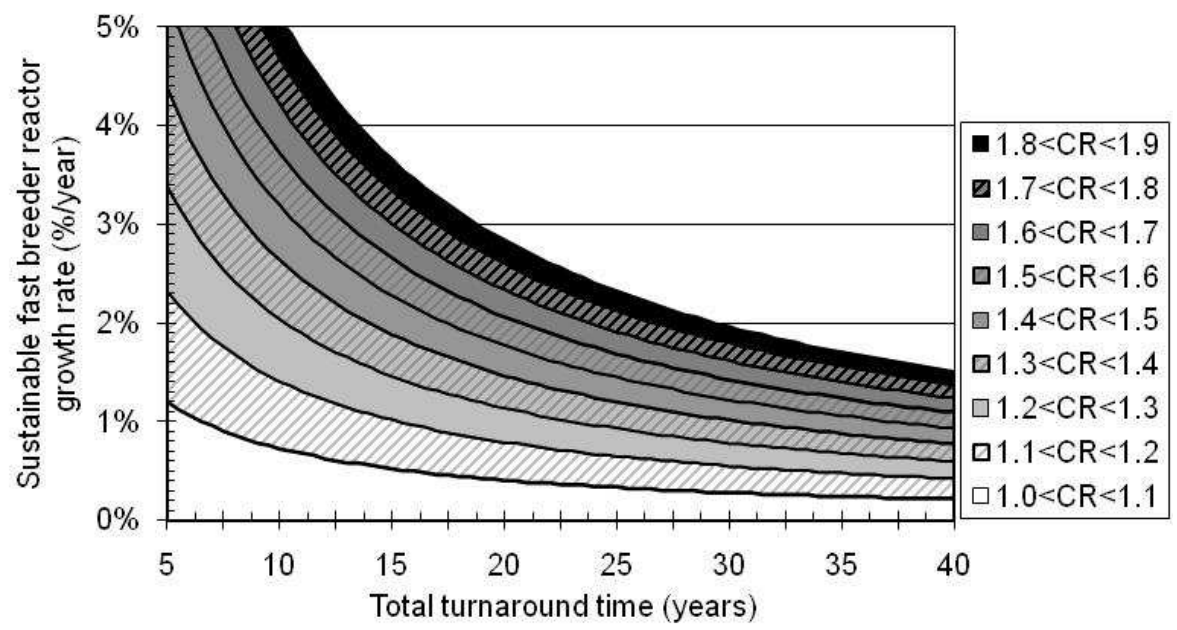

Fig. 18. Required fast reactor TRU conversion ratio at dynamic equilibrium, as a function of growth rate and turnaround, ignoring displacement of pre-existing LWRs or TRU stockpiles.

The theoretical maximum $\mathrm{CR}$ is $\sim 1.9$ because Pu239 dominates fission in a fast reactor and it yields 2.9 neutrons/fission. One neutron must induce the next fission, leaving 1.9 to make more transuranic material from U238. ${ }^{3}$ Neutron yields vary slightly by isotope, e.g., 2.4 for U235, 2.9 for Pu241, and 3.2 for Am242m, so the exact theoretical maximum could be slightly different than 1.9. Of course, as neutron leakage and neutron capture by fuel and non-fuel core material is accounted for, the practical maximum conversion ratio will be significantly lower than 1.9. For example, if that maximum is considered to be 1.5 , then the maximum rate of breeder reactor introduction can be $4.7 \%$ with 6 -year turnaround (onsite recycling), but only $2.3 \%$ with 15-year turnaround (offsite recycling). The holdup of transuranic material in the system impacts system performance so that short time lags, e.g., when facilities are co-located instead of at different locations, can lead to faster system evolution.

\footnotetext{
3 The theoretical maximum is actually smaller than 1.9 because some neutrons absorbed into fuel necessarily lead to $(n, \gamma)$ reactions instead of (n,fission). However, some of the $(n, \gamma)$ products and their successors will fission, so the reduction of the maximum below 1.9 is somewhat complicated and beyond the scope of this illustrative calculation.
} 


\subsection{Proliferation resistance and physical protection}

Barriers to acquisition of a nuclear weapon/explosive are called "proliferation resistance" for a host nation of nuclear facilities and "physical protection" for a subnational or terrorist group. An evaluation methodology should include the four stages toward a weapon - (1) diversion (if host nation) or theft (if subnational), (2) transportation, (3) transformation, and (4) weapon fabrication and indicate how the various indicators are to be combined.

First, observe that although there is significant reduction of TRU relative to once through (avoided and consumed), there remains significant TRU material throughout a fuel cycle system. Figure 19 illustrates that there is substantial reduction of TRU material relative to once-through (via avoidance and consumption) but also that there is substantial TRU in many parts of the system.

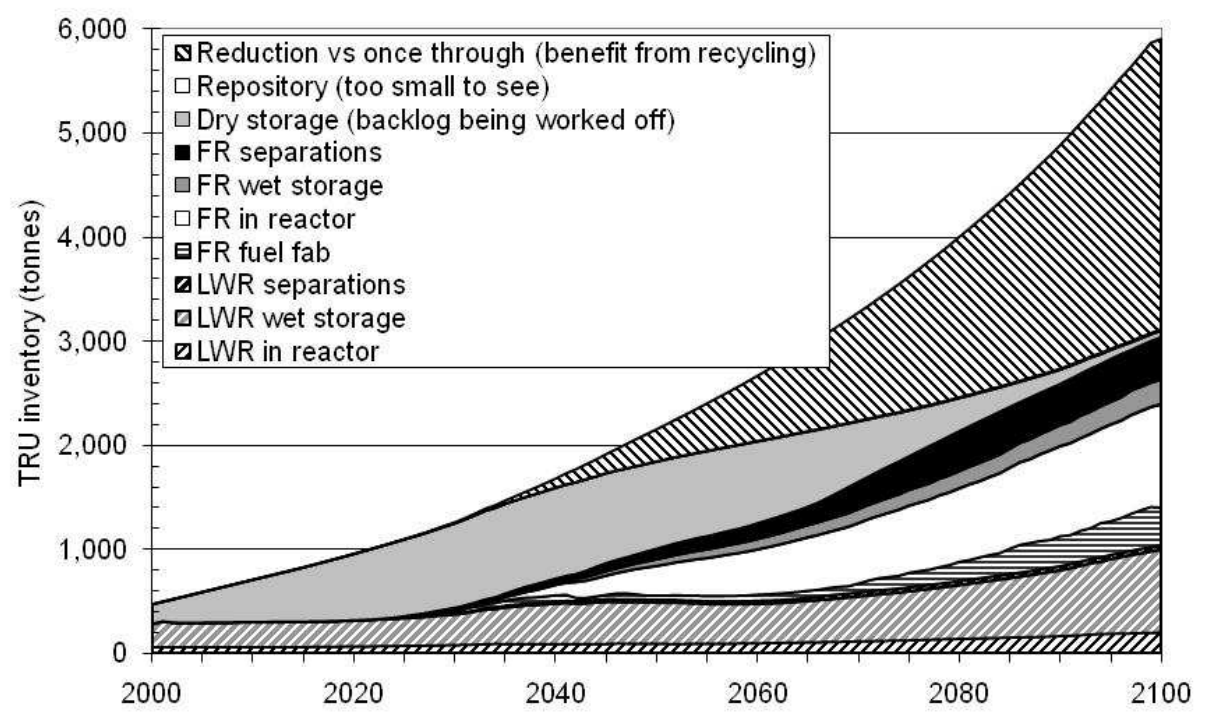

Fig. 19. Location of TRU material in a 1-tier recycle case.

The second proliferation resistance observation is that the mass flow of material through separations can vary significantly both quantitatively and by type of separation, independent of separation efficiency. Figure 20 shows the total mass sent through separations (the sum of the flow tonnes-TRU/yr times the number of years) as a function of fast reactor conversion ratio for a 1-tier simulation; this figure keeps the fast reactor fuel constant (metal) with onsite processing. As CR increases, there are fewer LWRs hence less processing of used LWR fuel; but there are more fast reactors and more processing of fast reactor fuel. These may be of different technologies and the siting strategy could differ, e.g., large centrally located aqueous separation of used UOX fuel versus at-reactor electrochemical separation of used fast reactor metal fuel. In such cases, the proliferation risk posed by different technologies and locations would vary.

The third proliferation resistance observation is that the recycled material composition will change significantly with time. Figure 21 shows evolution of the recycle mix as TRU material is repeatedly recycled, in this case as mixed oxide fuel in LWRs. ${ }^{12}$ This calculation 
uses heterogeneous inert matrix fuel (IMF) 4 to keep the material fissile, i.e., each recycle is a mixture of fresh UOX and IMF made with TRU recovered from the previous recycle. The figure shows that the $\mathrm{Cm}$ and $\mathrm{Cf}$ isotopes, which emit high numbers of neutrons, increase up to four orders of magnitude between the first recycle and equilibrium. Figure 21 compares MOX and metal fast reactor fuel (at $C R=0.75$, comparable to the $C R$ of MOX) at the first and equilibrium recycle. Both MOX-TRU and FR-TRU evolve considerably from the first to the equilibrium recycle. FR-TRU has higher Pu content but lower amounts of the highest TRU isotopes (Cf) that tend to dominate neutron emission.

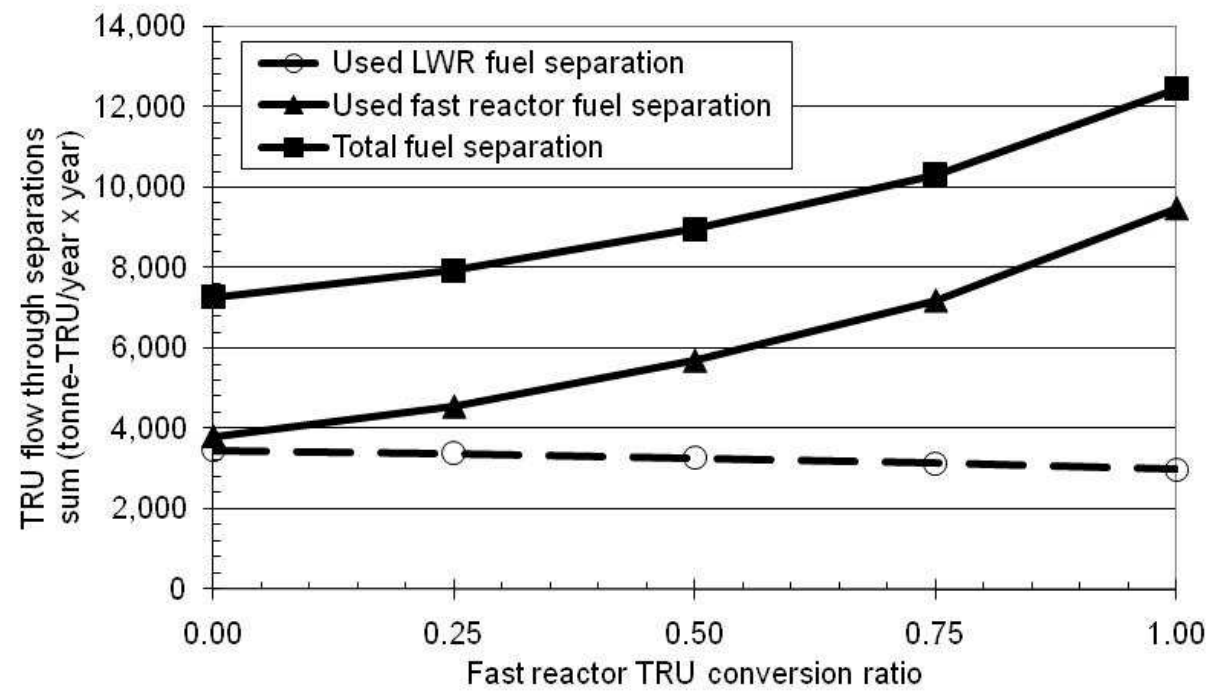

Fig. 20. Total mass of TRU material sent through separations in 1-tier recycle case as a function of fast reactor TRU conversion ratio; metal fuel, on-site processing assumed.

Figure 22 shows that MOX-TRU and FR-TRU vary little after the first recycle (square data points), with major differences only in the $\mathrm{Cf}$ isotopes. (Composition impacts many areas, not just proliferation and physical security.) At equilibrium recycle (circle data points), MOX-TRU and FR-TRU differ less than an order of magnitude below Cm244, about an order of magnitude from $\mathrm{Cm} 244$ to $\mathrm{Cm} 248$ and over an order of magnitude for the $\mathrm{Cf}$ isotopes. High gamma emitting isotopes are found throughout the actinide chain and therefore the total gamma comparison between MOX-TRU and FR-TRU is merely an order of magnitude. The highest neutron emitters are located at the top of the TRU chain and therefore the neutron emission comparison between MOX-TRU and FR-TRU grows over an order of magnitude. Still, both MOX and FR at equilibrium have higher gamma and neutron emission than either has at the start of recycling.

The fourth and final proliferation resistance observation is that the quality of $\mathrm{Pu}$ does not change dramatically throughout the century. The quality of Pu measured as the fraction of

4 MOX fuel has $U$ and one or more TRU elements mixed in each fuel pellet and fuel pin. A homogeneous IMF fuel has only TRU. A heterogeneous IMF fuel is a mix of IMF fuel pins and UOX fuel pins. 
$\mathrm{Pu}-239$ to total $\mathrm{Pu}$ in the system only changes from 0.55 (once through) to $\sim 0.50$ for the two recycle cases.



Fig. 21. Isotopic mix for discharged MOX-TRU as a function of how many times transuranic material is. Transmutation data from ref. 16.

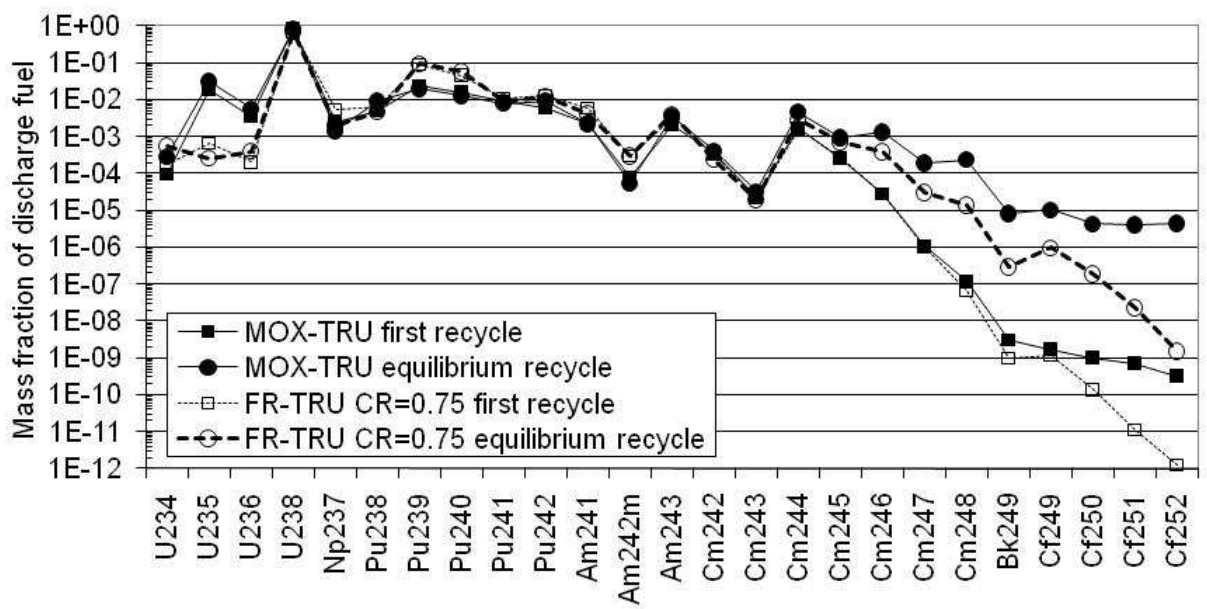

Fig. 22. Isotopic mix for discharged MOX-TRU and FR-metal-TRU for first and equilibrium recycle. Transmutation data from ref. 12 and 16.

\subsection{Economics}

In any area of technology, the cheapest situation occurs when raw materials are very low cost and one is allowed to just walk away from waste. As raw material cost increases, the incentive to recycle materials increase. As waste disposal costs increase, the incentive to reduce, re-use, and recycle increases. 
Unsurprisingly, therefore, for nuclear fuel cycles, there are major uncertainties associated with the future cost of uranium (or thorium), any waste repository, and any new technologies (reactors, fuels, separation, waste forms) that may be involved. Were uranium and waste disposal inexpensive, it would be difficult to economically justify new technologies.

The average cost of electricity from current U.S. nuclear power plants is less than $\$ 0.018 /$ kilowatt-hour or 18 mills/kilowatt-hour (18 mills/ $\mathrm{kW}-\mathrm{hr}$ ) because their capital costs have mostly been depreciated. Cost projections for new plants in the next decade range from 47 to 71 mills $/ \mathrm{kW}$-hr which include capital recovery. Fuel cycle costs are about 6 mills $/ \mathrm{kW}$ hr. Of this, 1 mill/ $\mathrm{kW}$-hr is the fee currently paid by U.S. utilities to the Federal government for future geologic disposal, covering projected disposal costs.

To date, estimates of the cost of relatively traditional alternative fuel cycle options (most uranium cost increases, Yucca Mtn repository, and GNEP technology options) suggest uncertainties of a few mills/kW-hr, and possible increased cost (relative to once through) ranging from zero to a few mills $/ \mathrm{kW}-\mathrm{hr}$, or $0-10 \%$ of total nuclear energy cost.

The first is that dynamic versus static will impact economic assessments. A static quilibrium is appropriate when discount rates, the time value of money, and cash flows are not addressed. A dynamic equilibrium comes closer to cash flows if the time value of money is accounted for as costs that lead others are given greater weight; cash flows that lag others are given less weight. Table III lists key lead and lag items in dynamic equilibria. For example, one builds LWRs relatively early in the process of generating electricity; therefore, when time value of money is considered, the relative contribution of LWRs to total cost increases. Conversely, fast reactors and waste disposal are bought relatively late; therefore, their relative contribution to total cost decreases.

\begin{tabular}{|c|c|c|}
\hline & $\begin{array}{l}\text { Leading } \\
\text { Purchase relatively soon }\end{array}$ & $\begin{array}{l}\text { Lagging } \\
\text { Purchase relatively late }\end{array}$ \\
\hline $\begin{array}{l}\text { Increase or decrease when } \\
\text { shifting from static to } \\
\text { dynamic equilibrium }\end{array}$ & $\begin{array}{l}\text { Increase, hence factor might } \\
\text { be more important than } \\
\text { predicted by static } \\
\text { equilibrium }\end{array}$ & $\begin{array}{l}\text { Decrease, smaller impact than } \\
\text { might be predicted by static } \\
\text { equilibrium }\end{array}$ \\
\hline Material inputs & $\begin{array}{l}\text { Natural uranium } \\
\text { Depleted uranium } \\
\text { Enriched uranium } \\
\text { Zirconium and steel }\end{array}$ & \\
\hline Types of reactors & $\begin{array}{l}\text { Number of thermal reactors } \\
\text { using uranium oxide fuel }\end{array}$ & $\begin{array}{l}\text { Number of fast reactors } \\
\text { Thermal efficiency increases }\end{array}$ \\
\hline Types of facilities & Fabrication plants & Separation plants \\
\hline Material output & & Waste disposal \\
\hline
\end{tabular}

Table 3. Lead and Lag Items in Dynamic Equilibria

The fraction of fast reactors in time will be much lower than predicted by simple "static equilibrium" calculations due to multiple system constraints that impact the amount of TRU available for fueling new reactors at startup. This is illustrated in figure 23. 


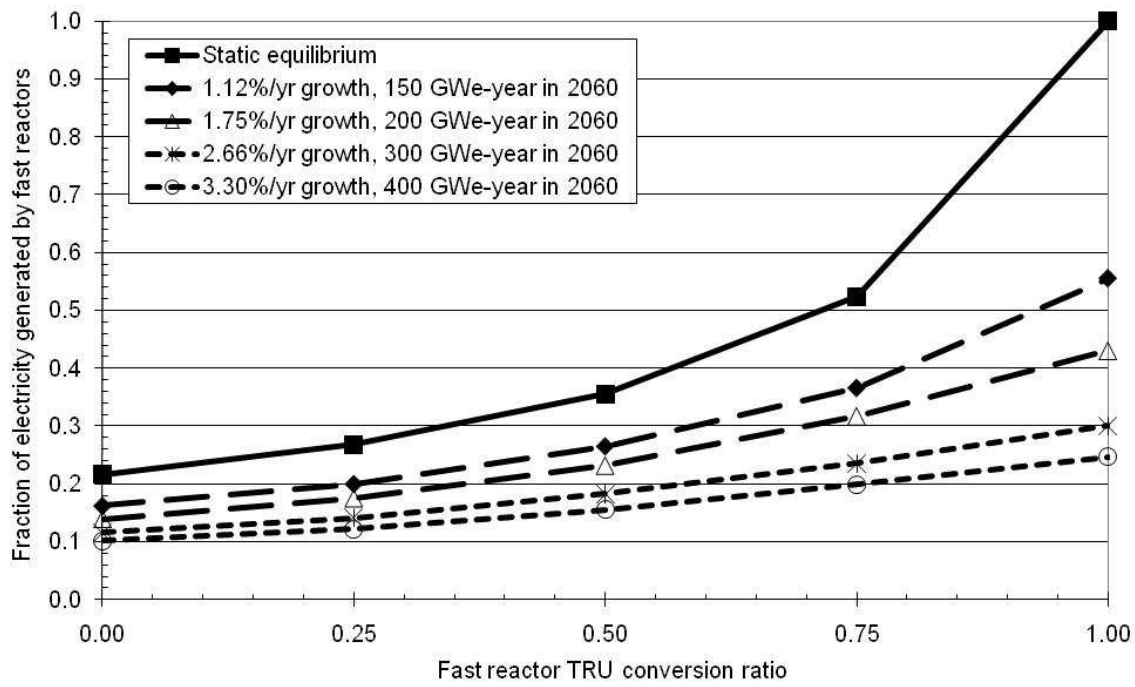

Fig. 23. Fraction of electricity generated by fast reactor at dynamic equilibrium (near 2100) as function of fast reactor TRU conversion rate and nuclear electricity power growth rate, calculations assumed metal fuel and onsite processing.

The final observation is that fuel and separation facilities must accommodate variation in fuel mixture elemental composition. This composition will vary as reactor type, fuel type, burnup, aging of used fuel, number of recycles, separation purity, etc.

\section{Acknowledgments}

This chapter was prepared for the U.S. Department of Energy Office of Nuclear Energy, Science, and Technology under DOE Idaho Operations Office Contract DE-AC07-05ID14517.

\section{References}

[1] U. S. Department of Energy, Office of Nuclear Energy, Science, and Technology, Report to Congress - Advanced Fuel Cycle Initiative: Objectives, Approach, and Technology Summary, May (2005).

[2] U. S. Department of Energy, Office of Nuclear Energy, Science and Technology, Advanced Fuel Cycle Initiative (AFCI) Comparison Report, FY 2005, May (2005).

[3] U. S. Department of Energy, Office of Nuclear Energy, Science, and Technology, Advanced Fuel Cycle Initiative (AFCI) Comparison Report, FY 2006 Update, July (2006).

[4] J. J. Jacobson, A.M. Yacout, G.E. Matthern, S.J. Piet, D.E. Shropshire, R.F. Jeffers, T. Schweitzer, "Verifiable Fuel Cycle Simulation Model (VISION): A tool for Analyzing Nuclear Fuel Cycle Futures", Nuclear Technology, Volume 172, Number 2, November 2010.

[5] S. J. Piet, "Selection of Isotopes and Elements for Fuel Cycle Analysis", Advances in Nuclear Fuel Management IV, April 12-15, 2009. 
[6] J. W. Forrester, Principles of Systems, Wright-Allen Press, Inc, 1971.

[7] Powersim Software AS, Bergen, Norway, www.powersim.com.

[8] J. Grouiller, G. Glamenbaum, B. Sicard, M. Mus, J. Martin, J. Devezeaux de Lavergne, O. Comellini. COSI, A Simulation Software for a Pool of Reactors and Fuel Cycle Plants: Application to the Study of the Deployment of Fast Breeder Reactors. Proceedings of the International Conference on Fast Reactors and Related Fuel Cycles, Kyoto, Japan, October 1991.

[9] C. G. Bathke and E. A. Schneider. Report of the COSI and NFCSim Benchmark. Los Alamos National Laboratory (2003). LA-UR-03-8051.

[10] J. A. Stillman, "Homogeneous Recycling Strategies in LWRs for Plutonium, Neptunium, and Americium Management," Argonne National Laboratory, ANLAFCI-124, August 2004.

[11] E. A. Hoffman, W. S. Yang, R. N. Hill, Preliminary Core Design Studies for the Advanced Burner Reactor over a Wide Range of Conversion Ratios, ANL-AFCI177, September 29, 2006.

[12] E. A. Hoffman, "Updated Design Studies for the Advanced Burner Reactor over a Wide Range of Conversion Ratios," Argonne National Laboratory report, ANLAFCI-189, May 31 (2007).

[13] E. A. Hoffman, "FY09 ANL AFCI Transmutation Studies," Argonne National Laboratory report, ANL-AFCI-271, August 31 (2007).

[14] M. Asgari, B. Forget, S. Piet, R. Ferrer, S. Bays, Computational Neutronics Methods and Transmutation Performance Analyses for Light Water Reactors, INL/EXT-0712472, March 2007.

[15] R. M. Ferrer, M. Asgari, S. E. Bays, B. Forget, "Fast Reactor Alternative Studies: Effects of Transuranic Groupings on Metal and Oxide Sodium Fast Reactor Designs," INL/EXT-07-13236, September 2007.

[16] G. Youinou and S. Bays, "Homogeneous recycling of Pu or Pu with Minor Actinides in PWRs loaded with MOX-UE fuel (MOX with U-235 enriched U support), INL/EXT-09-16091, AFCI-SYSA-TRAN-SS-RT-2009-000055, June (2009).

[17] OECD Nuclear Energy Agency, Nuclear Fuel Cycle Transition Scenario Studies Status Report (2009).

[18] S. J. PIET, G. E. Matthern, J. J. Jacobson, C. T. Laws, L. C. Cadwallader (INL), A. M. Yacout, R. N. Hill (ANL), J. D. Smith, A. S. Goldmann, G. Bailey (SNL), “Fuel Cycle Scenario Definition, Evaluation, and Trade-offs," INL report, INL/EXT-06-11683, August (2006).

[19] OECD Nuclear Energy Agency and International Atomic Energy Agency, Uranium 2007: Resources, Production and Demand, NEA No. 6345 (2008).

[20] J. S. Herring, "Uranium and Thorium Resources," in The Encyclopedia of Energy, Cutler J. Cleveland, editor in chief, Academic Press, (2004).

[21] J. J. Steyn, "Uranium Resources: Need For 21st Century Advanced Fuel Cycles," Energy Resources International, Inc., NEI International Fuel Seminar (2003).

[22] D. J. Rose, Learning About Energy, Plenum Press, New York (1986). 


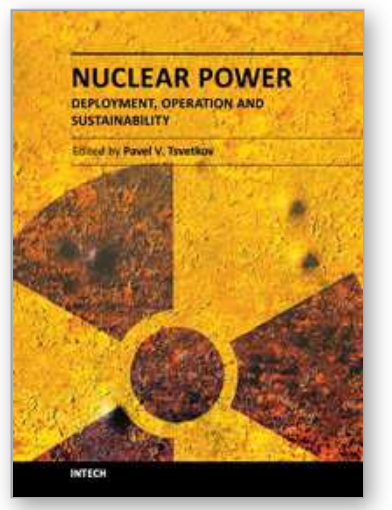

\author{
Nuclear Power - Deployment, Operation and Sustainability \\ Edited by Dr. Pavel Tsvetkov
}

ISBN 978-953-307-474-0

Hard cover, 510 pages

Publisher InTech

Published online 09, September, 2011

Published in print edition September, 2011

We are fortunate to live in incredibly exciting and incredibly challenging time. Energy demands due to economic growth and increasing population must be satisfied in a sustainable manner assuring inherent safety, efficiency and no or minimized environmental impact. These considerations are among the reasons that lead to serious interest in deploying nuclear power as a sustainable energy source. At the same time, catastrophic earthquake and tsunami events in Japan resulted in the nuclear accident that forced us to rethink our approach to nuclear safety, design requirements and facilitated growing interests in advanced nuclear energy systems. This book is one in a series of books on nuclear power published by InTech. It consists of six major sections housing twenty chapters on topics from the key subject areas pertinent to successful development, deployment and operation of nuclear power systems worldwide. The book targets everyone as its potential readership groups - students, researchers and practitioners - who are interested to learn about nuclear power.

\title{
How to reference
}

In order to correctly reference this scholarly work, feel free to copy and paste the following:

J. J. Jacobson, G. E. Matthern and S. J. Piet (2011). Assessment of Deployment Scenarios of New Fuel Cycle Technologies, Nuclear Power - Deployment, Operation and Sustainability, Dr. Pavel Tsvetkov (Ed.), ISBN: 978953-307-474-0, InTech, Available from: http://www.intechopen.com/books/nuclear-power-deploymentoperation-and-sustainability/assessment-of-deployment-scenarios-of-new-fuel-cycle-technologies

\section{INTECH}

open science | open minds

\section{InTech Europe}

University Campus STeP Ri

Slavka Krautzeka 83/A

51000 Rijeka, Croatia

Phone: +385 (51) 770447

Fax: +385 (51) 686166

www.intechopen.com

\section{InTech China}

Unit 405, Office Block, Hotel Equatorial Shanghai

No.65, Yan An Road (West), Shanghai, 200040, China

中国上海市延安西路65号上海国际贵都大饭店办公楼405单元

Phone: +86-21-62489820

Fax: $+86-21-62489821$ 
(C) 2011 The Author(s). Licensee IntechOpen. This chapter is distributed under the terms of the Creative Commons Attribution-NonCommercialShareAlike-3.0 License, which permits use, distribution and reproduction for non-commercial purposes, provided the original is properly cited and derivative works building on this content are distributed under the same license. 